\title{
LA GANADERÍA ECOLÓGICA EN LA GESTIÓN DE LOS ESPACIOS NATURALES PROTEGIDOS: ANDALUCÍA COMO MODELO
}

\author{
ORGANIC LIVESTOCK AS A MANAGEMENT TOOL FOR PROTECTED NATURAL \\ AREASINANDALUSIA
}

Díaz Gaona, C. ${ }^{1}$; Sánchez Rodríguez, M. ${ }^{\text {; }}$ Gómez Castro, G. ${ }^{1}$ y Rodríguez Estévez, V. ${ }^{1 *}$

${ }^{1}$ Cátedra de Ganadería Ecológica Ecovalia. Departamento de Producción Animal. Universidad de Córdoba. Campus de Rabanales. Córdoba. España. *pa2roesv@uco.es

\section{PaLABRAS CLAVE ADICIONALES}

Medioambiente. Conservación. Externalidades positivas. Pastoreo.

\section{RESUMEN}

La mayoría de los espacios naturales protegidos (ENP) ha conservado sus valores ambientales gracias al uso racional que de sus recursos han hecho sus pobladores durante siglos. Uno de los principales usos productivos ha sido la ganadería extensiva, cuyo abandono por pérdida de rentabilidad o por intensificación repercute negativamente sobre la conservación de estos ENP.

En este trabajo se estudia el papel de la ganadería extensiva en la conservación de los ENP, utilizando la Comunidad Autónoma de Andalucía como modelo, con unas 200000 ha de ganadería ecológica (GE) situadas en ENP los cuales, ocupan el 19,5 \% de Andalucía (es la comunidad autónoma española con más territorio protegido) ahi se encuentra más del $30 \%$ de las explotaciones de GE, con una carga ganadera media de 0,22 UGM/ha. Finalmente, se plantea la implantación de la GE como una herramienta de gestión sostenible de los ENP, por ser de carácter voluntario y por facilitar los requerimientos de la administración de los ENP (evitar contaminación, erosión, sobrepastoreo, etc.); además de promover ayudas compensatorias para los agricultores y ganaderos por su labor como conservadores del medio.

\section{SUMMARY}

Most of protected natural areas (PNA) have conserved their environmental values by their

\section{AdDitiOnAL KEYWORDS}

Environment. Conservation. Positive externalities. Grazing.

inhabitants ancient rational use of resources. One of the main productive uses has been extensive livestock farming, which has been abandoned due to a lack of profitability or intensified; both negatively affecting PNA conservation. Andalusia is considered a model region because is the Spanish one with more protected territory (PNA take up $19.5 \%$ of the region) and it has 200000 ha dedicated to organic livestock farming (OF); these included $>30 \%$ of OF farms, with an average stocking rate of $0.22 \mathrm{LU} / \mathrm{ha}$. Finally, OF is proposed as a tool for PNA sustainable management, because it is voluntary and facilitates PNA authorities requirements (avoiding contamination, erosion, overgrazing, etc.); besides it can promote a subsidy support for farmers to compensate their conservation function.

\section{INTRODUCCIÓN}

Actualmente el establecimiento de áreas protegidas es, a nivel mundial, la herramienta más común para la conservación in situ de la biodiversidad. En muchas ocasiones, la protección de esas áreas restringe a sus pobladores determinados derechos de acceso a recursos importantes para ellos, lo que incide negativamente en su bienestar social y económico y, consecuentemente, genera un rechazo en esas poblaciones que 
dificulta alcanzar el objetivo de conservación perseguido (Ferraro, 2008).

Para evitar este sinsentido, debe buscarse un equilibrio entre los intereses conservacionistas de la sociedad y las autoridades, y los derechos de uso de los propietarios y pobladores del territorio, cuyas circunstancias y modos de aprovechamiento han mantenido los valores que se pretenden conservar.

De hecho, en el Congreso Mundial de Parques de la Unión Mundial para la Naturaleza (IUCN) celebrado en 2003 en Durban (Sudáfrica), se declaró que los perjuicios que se generan a los campesinos de las áreas protegidas deberían sufragarse institucionalmente, especialmente en las comunidades pobres.

Atendiendo a estas razones, el objetivo del programa de la IUCN para el periodo 2013-2016, aprobado en el último Congreso Mundial de la Naturaleza, celebrado en Jeju (Corea del Sur) en septiembre de 2012 (IUCN, 2012) es movilizar a las comunidades que trabajan para la conservación de la biodiversidad, el desarrollo sostenible y la reducción de la pobreza.

Las prácticas tradicionales conjuntas de la agricultura y ganadería, mediante su integración en la dinámica del ecosistema han ido moldeando gran parte del paisaje, siguiendo un modelo de sostenibilidad cultural que ha permitido la llegada hasta hoy de estos ecosistemas que constituyen en el momento actual buena parte de las áreas protegidas (Rodríguez-Estévez et al., 2010a).

La ganadería ecológica (GE), actividad reconocida globalmente, se basa en esas prácticas agrarias tradicionales, y por ello, en el contexto de la ganadería extensiva, puede convertirse en el instrumento de elección a la hora de gestionar las áreas protegidas.

\section{OBJETIVOS}

En este trabajo se estudia la importancia de la ganadería extensiva en la gestión y conservación de los espacios naturales protegidos (ENP), tanto en la preservación del medio ambiente, como en su función de principal actividad productiva de los mismos.

Igualmente, se estudiará cómo están afectando a los ENP andaluces los cambios que está soportando la ganadería extensiva, y la importancia que su conversión a GE puede tener en su gestión, para compatibilizar los intereses de la Administración y los de los propietarios-productores.

\section{LOSESPACIOSNATURALES PROTEGIDOS}

El origen de los ENP, tal y como hoy se entienden, se encuentra en la voluntad social de evitar la desaparición de lugares excepcionales destacados por la grandiosidad de sus paisajes, la riqueza o singularidad de su fauna y flora, o por su estado primigenio (Gómez-Limón et al., 2008).

Según la Unión Mundial para la Naturaleza (IUCN), un ENP es una zona de tierra o mar especialmente dedicada a la protección y mantenimiento de la diversidad biológica y de los recursos naturales y culturales asociados y gestionados legalmente o por otros métodos eficaces (IUCN, 1994), no sólo con la pretensión de conservar el ecosistema, sino también de promover su uso sostenible y racional, haciendo posible su aprovechamiento sin producir su degradación y agotamiento (Heywood e Iriondo, 2003).

El incremento de la conciencia conservacionista ha dado lugar a que, en los últimos 25 años, el número de ENP haya aumentado de manera exponencial. En el mundo, existen más de 100000 ENP, que cubren más del $12 \%$ de la superficie terrestre (Chape et al., 2005). Su fin primordial es garantizar los servicios que proporcionan los ecosistemas y conservar sus valores patrimoniales (Gómez-Limón et al., 2008) y, aunque no son la única vía, constituyen actualmente el principal instrumento de gestión directa 
aplicado a la conservación de la naturaleza. Por ello son reconocidos como las unidades básicas para la conservación, representando, además, una de las más importantes asignaciones de uso de recursos humanos del planeta (Chape et al., 2005).

Según Marañón et al. (2012), el análisis de la multitud de servicios que proporcionan los ecosistemas forestales pone en evidencia la dependencia de este capital natural a múltiples niveles (económico, alimenticio, cultural, psicológico, etc.). Los principales objetivos de los ENP son integrar las áreas protegidas en la planificación territorial con las políticas de sectores como la agricultura, silvicultura y turismo, que deberían ser favorables para el medio ambiente. Para ello se necesitan leyes efectivas e instituciones eficaces para planificar y gestionar los ENP; un plan de gestión para cada espacio protegido, zonificar los grandes espacios protegidos para hacer compatible agricultura tradicional y turismo con la conservación de la naturaleza y del paisaje; y mejorar la cualificación y formación del personal de los espacios protegidos (IUCN, 1994). En este sentido, actualmente toman mayor valor las áreas protegidas que permiten el uso de sus recursos locales (NaughtonTreves et al., 2005).

El papel de los ENP en la conservación de la naturaleza es muy amplio. A veces, sirven como instrumento preventivo de la ordenación territorial impidiendo la dispersión urbanística o invirtiendo para mantener la singularidad de un paisaje. En otras ocasiones, promueven el mantenimiento de actividades económicas beneficiosas para el territorio. A menudo, concentran sus esfuerzos en la comunicación con el público y la prestación de servicios recreativos y turísticos. También, con cierta frecuencia, se concentran en la vigilancia y en el control de las actividades lesivas para ciertas especies. Además, los ENP contribuyen a estimular las actividades que más favorezcan la conservación (Gómez-Limón et al., 2000).

Las características sobre la protección de un espacio natural han madurado con el tiempo y actualmente son numerosas y variadas, pero en la mayoría de ellas se aprecian dos a destacar: los méritos de protección y el carácter efectivo de la protección (Tolón Becerra y Lastra Bravo, 2008).

\section{REGULACIÓN LEGALDELOS ESPACIOSNATURALES PROTEGIDOSENEUROPA}

En Europa, con el objetivo de mantener o restablecer, en un estado de conservación favorable, los hábitats naturales y las especies silvestres de la fauna y de la flora de interés comunitario, se designan zonas especiales de conservación (ZEC), establecidas de acuerdo con la directiva hábitat (Directiva 92/43/CEE, de 21 de mayo de 1992, sobre la conservación de los hábitats naturales de fauna y flora silvestres) (CEE, 1992), así como zonas de especial protección para las aves (ZEPA) establecidas según la directiva aves (Directiva 2009/147/CE del Parlamento Europeo y del Consejo de 30 de noviembre de 2009 relativa a la conservación de las aves silvestres, que deroga a la Directiva 79/409/CEE) (CEE, 2010). Estas zonas se encuentran integradas en una red ecológica europea coherente, denominada Natura 2000, que fue creada por la directiva hábitat (CEE, 1992), y que es actualmente el principal instrumento de la UE para el mantenimiento de la biodiversidad.

Esta directiva señala además la conveniencia de fomentar la gestión de esas zonas en las políticas de desarrollo y de ordenación del territorio. De hecho, las medidas que se adopten deberán tener en cuenta las exigencias económicas, sociales y culturales, así como las particularidades regionales y locales. En este sentido, para alcanzar el objetivo general de un desarrollo duradero, en determinados casos, se podrá requerir el mantenimiento, e incluso el estímulo, de actividades humanas.

Así mismo, la directiva hábitat considera imprescindible que se fomente la investi- 
gación y los trabajos científicos necesarios para mejorar los conocimientos científicos y técnicos requeridos para la aplicación efectiva de la misma. La educación y la información general relativas a estos objetivos resultan indispensables.

\section{REGULACIÓN LEGAL DE LOS ESPA- CIOSNATURALESPROTEGIDOSEN ESPAÑA}

Las primeras medidas legales de protección de los espacios naturales españoles datan de 1916, con la ley de parques nacionales, a la que siguió la Real Orden de 1927 donde se establecían las figuras de sitios y monumentos naturales. Posteriormente se promulgó la Ley de Montes en 1957, que derogaba la de 1916 y asumía la gestión de espacios naturales (Mulero, 2002). En esos modelos de conservación, predominó la idea de no intervención, reservándose ciertas áreas de la explotación humana para que se pudiera disfrutar de su contemplación como museos de la naturaleza (Vacas Guerrero, 2005).

En 1975, se publicó la Ley 15/1975, de 2 de mayo, de espacios naturales protegidos (Jefatura del Estado, 1975), que incluía la figura parque natural, lo que supuso una aportación de gran trascendencia en las políticas protectoras posteriores, ya que entre sus objetivos se encontraba facilitar el contacto del hombre con la naturaleza y armonizar la conservación de los valores naturales que encierra el espacio con un aprovechamiento ordenado de sus recursos, lo que supuso un cambio importante respecto a la filosofía conservacionista dominante a nivel mundial, que consideraba como espacios a proteger aquéllos no transformados o poco modificados por la explotación y ocupación humanas (Vacas Guerrero, 2005).

Más tarde, en 1989, se aprobó la Ley 4/ 1989, de 27 de marzo, de conservación de los espacios naturales y de la flora y fauna silvestres (Jefatura del Estado, 1989) que regulaba la gestión de los ENP en España. Sus principios inspiradores fueron el mantenimiento de los procesos ecológicos esenciales y de los sistemas vitales básicos; la preservación de la diversidad genética; la utilización ordenada de los recursos garantizando el aprovechamiento sostenido de las especies y de los ecosistemas, su restauración y mejora; y la preservación de la variedad, singularidad y belleza de los ecosistemas naturales y del paisaje. Con esta ley se pretendía establecer la importancia y la necesidad de ordenación de los recursos naturales del estado, extendiendo el régimen jurídico que los protegía más allá de los meros ENP que, más que un fin, serían una herramienta que coadyuvaría al mantenimiento de la biodiversidad y a la utilización racional de los recursos naturales $(\mathrm{Mu}-$ lero, 2002). Para ello, su aportación esencial fue el establecimiento de los planes de ordenación de recursos naturales (PORN), que se concibieron como el instrumento básico para la planificación futura del medio natural (Mulero, 2002).

La Ley 4/1989 estableció cuatro figuras de protección de preferencia, que son:

Parques: son áreas naturales, poco transformadas por la explotación и ocupación humana que, en razón a la belleza de sus paisajes, la representatividad de sus ecosistemas o la singularidad de su flora, de su fauna o de sus formaciones geomorfológicas, poseen unos valores ecológicos, estéticos, educativos y científicos cuya conservación merece una atención preferente. En ellos se podrá limitar el aprovechamiento de sus recursos naturales, y se facilitará la entrada de visitantes con las limitaciones precisas para garantizar la protección de aquéllos.

Reservas naturales: son espacios naturales, cuya creación tiene como finalidad la protección de ecosistemas, comunidades o elementos biológicos que, por su rareza, fragilidad, importancia o singularidad merecen una valoración especial. En ellas estará limitada la explotación de re- 
cursos, salvo en aquellos casos en que esta explotación sea compatible con la conservación de los valores que se pretenden proteger, y con carácter general, estará prohibida la recolección de material biológico o geológico.

Monumentos naturales: son espacios o elementos de la naturaleza constituidos básicamente por formaciones de notoria singularidad, rareza o belleza, que merecen ser objeto de una protección especial; considerándose también monumentos naturales, las formaciones geológicas, los yacimientos paleontológicos y demás elementos de la gea que reúnan un interés especial por la singularidad o importancia de sus valores científicos, culturales o paisajísticos.

Paisajes protegidos: son lugares concretos del medio natural que, por sus valores estéticos y culturales, sean merecedores de una protección especial.

Además, esta ley contempló la posibilidad de que las autonomías empleasen otras figuras de protección distintas en sus respectivos territorios (Jefatura del Estado, 1989), tales como refugio de fauna, monumento natural, enclave natural, paisaje protegido, paraje natural, paraje pintoresco, sitio de interés científico, biotopo protegido, etc.

La Ley 4/1989 fue derogada por la Ley 42/2007, de 13 de diciembre, del Patrimonio Natural y de la Biodiversidad (Jefatura del Estado, 2007), que establece el marco normativo de carácter básico y específico que rige sobre los espacios protegidos en España; y por la Ley 5/2007 que desarrolla específicamente los parques nacionales, su red y los mecanismos de gestión.

La Ley 42/2007 mantiene la figura, definición y regímenes de protección de los parques y de las reservas naturales de la Ley 4/1989, adaptando la definición de los paisajes protegidos al convenio europeo del paisaje (Consejo de Europa, 2000). Este convenio tiene como objetivo promover la protección, gestión y ordenación de los paisajes, así como organizar la cooperación europea en ese campo, y que fue ratificado en España el 26 de noviembre de 2007 (Jefatura del Estado, 2008).

La Ley 42/2007 desarrolla la red ecológica europea natura 2000, compuesta por los lugares de importancia comunitaria (hasta su transformación en zonas especiales de conservación), las zonas especiales de conservación y las zonas de especial protección para las aves, y reciben la denominación específica de espacios protegidos red natura 2000, con el alcance y las limitaciones que las comunidades autónomas establezcan en su legislación y en los correspondientes instrumentos de planificación. También se recogen las áreas protegidas por instrumentos internacionales (humedales de importancia internacional, sitios naturales de la lista del patrimonio mundial, áreas marinas protegidas del Atlántico del nordeste (OSPAR), zonas especialmente protegidas de importancia para el Mediterráneo (ZEPIM), geoparques, reservas de la biosfera y reservas biogenéticas), según lo dispuesto en los convenios y acuerdos internacionales en los que participa España.

Tolón Becerra y Lastra Bravo (2008) revisan el concepto de ENP, enriquecido con el paso del tiempo, y repasan su evolución en España desde los orígenes, detectando tres grandes etapas que se corresponden con tres enfoques y maneras de abordar esta institución (tabla I).

Los ENP de España incluyen, actualmente, 14 parques nacionales que son espacios emblemáticos, pero que suponen sólo el 0,7\% del territorio. La figura legal más utilizada en España es la de parque natural (PN), con 157 PN que cubren 3,7 millones de ha (tabla II), el 7,3\% del territorio español. El resto de superficie protegida, aproximadamente un $5 \%$ del territorio nacional, se reparte entre 344 monumentos naturales, 280 reservas naturales, 54 paisajes protegidos y otras figuras menores (tabla II).

En España hay un total de 6114405 ha terrestres protegidas (Múgica et al., 2010a), 
Tabla I. Resumen de las principales características de las distintas etapas en la evolución de los espacios naturales protegidos (ENP). (Summary of the main characteristics of the protected natural areas (ENP) different evolution stages.

\begin{tabular}{|c|c|c|c|}
\hline & $\begin{array}{c}\text { Primera etapa } \\
(1872-1975)\end{array}$ & $\begin{array}{c}\text { Segunda etapa } \\
(1975-1992)\end{array}$ & $\begin{array}{l}\text { Tercera etapa } \\
\quad \text { (Actual) }\end{array}$ \\
\hline $\begin{array}{l}\text { Definición de la etapa: } \\
\text { aspectos resaltables }\end{array}$ & $\begin{array}{l}\text { Nacimiento y conso- } \\
\text { lidación de los } \\
\text { primeros ENP }\end{array}$ & $\begin{array}{l}\text { Crecimiento y desarrollo } \\
\text { del sistema ENP }\end{array}$ & $\begin{array}{l}\text { Vinculación de los ENP } \\
\text { al desarrollo sostenible. } \\
\text { Consolidación de los ac- } \\
\text { tuales sistemas de ENP }\end{array}$ \\
\hline $\begin{array}{l}\text { Concepción de los } \\
\text { ENPy enfoque de } \\
\text { política de ENP }\end{array}$ & $\begin{array}{l}\text { Elitista y estática } \\
\text { (Santuarios naturales) } \\
\text { Políticas aisladas y } \\
\text { cerradas }\end{array}$ & $\begin{array}{l}\text { Apertura de la política } \\
\text { de ENP e interrelación } \\
\text { con otros sectores }\end{array}$ & $\begin{array}{l}\text { Integración en la política } \\
\text { global de conservación } \\
\text { y desarrollo sostenible }\end{array}$ \\
\hline Finalidades & Protección y recreativa & $\begin{array}{l}\text { Protección, conservación, } \\
\text { científica, cultural, edu- } \\
\text { cativa y socioeconómica }\end{array}$ & $\begin{array}{l}\text { Reforzamiento de las } \\
\text { finalidades de educación } \\
\text { ambiental y socioeco- } \\
\text { nómica }\end{array}$ \\
\hline Superficie protegida & Escasa & $\begin{array}{l}\text { Crecimiento espectacu- } \\
\text { lar en número de decla- } \\
\text { raciones y en superficie } \\
\text { protegida }\end{array}$ & $\begin{array}{l}\text { Crecimiento moderado, } \\
\text { o estabilizado }\end{array}$ \\
\hline $\begin{array}{l}\text { Tipología de figuras } \\
\text { proteccionistas }\end{array}$ & $\begin{array}{l}\text { Pocas figuras: } \\
\text { predominio del Parque } \\
\text { Nacional }\end{array}$ & $\begin{array}{l}\text { Proliferación de figuras: } \\
\text { confusión tipológica. } \\
\text { Nacimiento y gran } \\
\text { repercusión en Europa } \\
\text { de la figura PNR }\end{array}$ & $\begin{array}{l}\text { Tendencia a una } \\
\text { simplificación tipológica } \\
\text { y a unificar criterios. } \\
\text { Transición de los RB } \\
\text { hacia las URDS. }\end{array}$ \\
\hline Redes de ENP & $\begin{array}{l}\text { Prácticamente } \\
\text { inexistentes }\end{array}$ & $\begin{array}{l}\text { Creación y desarrollo } \\
\text { de las primeras redes }\end{array}$ & $\begin{array}{l}\text { Ampliación y reforza- } \\
\text { miento de las redes } \\
\text { regionales e internacio- } \\
\text { nales }\end{array}$ \\
\hline $\begin{array}{l}\text { Organismos y } \\
\text { disposiciones } \\
\text { internacionales }\end{array}$ & $\begin{array}{l}\text { Nacimiento de los } \\
\text { primeros organismos } \\
\text { especializados (IUCN, } \\
\text { WWF,...) y primeras } \\
\text { disposiciones }\end{array}$ & $\begin{array}{l}\text { Proliferación de } \\
\text { organismos y } \\
\text { disposiciones. Aumento } \\
\text { del número de países } \\
\text { suscribientes }\end{array}$ & $\begin{array}{l}\text { Reforzamiento del } \\
\text { papel de los organis- } \\
\text { mos y disposiciones }\end{array}$ \\
\hline $\begin{array}{l}\text { Instrumentos } \\
\text { utilizados para el } \\
\text { cumplimiento de } \\
\text { las finalidades }\end{array}$ & $\begin{array}{l}\text { Predominio de los } \\
\text { instrumentos jurídicos }\end{array}$ & $\begin{array}{l}\text { Desarrollo de la } \\
\text { planificación de la } \\
\text { gestión }\end{array}$ & $\begin{array}{l}\text { Utilización de nuevos in- } \\
\text { ventarios, indicadores } \\
\text { modelos de desarrollo } \\
\text { socioeconómico.... }\end{array}$ \\
\hline
\end{tabular}

Fuente: Tolón Becerra y Lastra Braco (2008). 
lo que supone un $12,1 \%$ del territorio nacional (tabla II). De todas ellas, destaca la figura PN que comprende el 53,4 \% de la superficie protegida a nivel nacional.

En total, y en respuesta a directivas europeas, España contribuye a la red natura 2000 con 14 millones de ha, el $28 \%$ del territorio español; aunque el $43 \%$ de esta superficie coincide con ENP ya declarados con anterioridad.

\section{LOSESPACIOSNATURALES PROTEGIDOSENANDALUCÍA: LOSPARQUES NATURALES}

Los ENP andaluces suelen ubicarse en medios montañosos, poco aptos para el cultivo y con la tradicional complementariedad entre las diversas actividades desarrolladas en los mismos, lo que ha permitido la conservación del bosque mediterráneo y una economía ganadera, manteniendo un status equilibrado y dinámico (Domenech García et al., 1999). Dada la variedad de ecosistemas y la extensión de los ENP de Andalucía, éstos deberían ser un modelo de gestión y aprovechamiento de los recursos para el resto del territorio nacional (Rodríguez-Estévez et al., 2010a).

Andalucía es la comunidad autónoma con más superficie protegida (1 702042 ha), reuniendo el 27,8 \% de la superficie protegida en España. De los 154 ENP andaluces, 24 corresponden a parques naturales (PN) que suponen el 83,6\% del total de la superficie protegida en Andalucía (tabla III) y el $16,3 \%$ de las 8726800 ha que ocupa el territorio de la comunidad (Consejería de Medio Ambiente, 2010). Los PN andaluces son los espacios que más superficie protegida aportan al conjunto nacional de ENP (23,3\%).

En Andalucía, la primera norma de protección de espacios naturales fue la Ley 2/ 1989 de Inventario de espacios naturales protegidos (Presidencia. Junta de Andalucia, 1989); en ella se basan las declaraciones de sus 24 PN (figura 1). Esta ley parte del objetivo de impulsar un sistema de áreas protegidas con un planeamiento integral de desarrollo económico y gestión, compatibles con la protección a partir de los PORN. En su exposición de motivos se indica que la diversidad y magnitud de la riqueza ecológica de Andalucía y la evidencia de la huella humana sobre los espacios naturales, permite propiciar una política de conservación compatible con el desarrollo económico.

En general, la idea de conservación debe entenderse en sentido amplio, por lo que, inherente a la misma, tiene que ir aparejado

Tabla II. Superficie protegida en España y número de espacios protegidos (ENP) por figura de protección. (Surface protected in Spain and number of protected natural areas (ENP) according to the kind of protection).

\begin{tabular}{|c|c|c|c|}
\hline Figura de protección & Número de ENP & Superficie por figura* (ha) & $\%$ de la superficie protegida \\
\hline Parque Nacional & 14 & 347081 & 5,0 \\
\hline Parque Natural & 157 & 3707958 & 53,4 \\
\hline Reserva Natural & 280 & 169501 & 2,4 \\
\hline Monumento Natural & 344 & 98940 & 1,4 \\
\hline Paisaje Protegido & 54 & 150096 & 2,2 \\
\hline Otras figuras autonómicas & 835 & 2470495 & 35,6 \\
\hline
\end{tabular}

*La superficie por figuras legales no puede sumarse ya que hay cierto grado de solapamiento territorial. Fuente: Múgica et al. (2010b). 
Tabla III. Los espacios naturales protegidos en Andalucía. (Protected natural areas in Andalusia).

\begin{tabular}{|c|c|c|}
\hline & Número & $\begin{array}{l}\text { Superficie } \\
\text { (ha) }\end{array}$ \\
\hline Parques nacionales & 2 & 140135 \\
\hline Parques naturales & 24 & 1422030 \\
\hline Reservas naturales & 28 & 21731 \\
\hline Otras figuras de protección & $n^{*} 100$ & 118146 \\
\hline Total de ENP en Andalucía & 154 & 1702042 \\
\hline \multicolumn{3}{|c|}{$\begin{array}{l}\text { Fuente: Consejería de Medio Ambiente. Junta de } \\
\text { Andalucía (2010). } \\
{ }^{*} \text { Otras figuras de protección: incluye parajes na- } \\
\text { turales, reservas naturales concertadas, par- } \\
\text { ques periurbanos, paisajes protegidos y monu- } \\
\text { mentos naturales. }\end{array}$} \\
\hline
\end{tabular}

el fomento de la riqueza económica, de forma que el aprovechamiento ordenado de los recursos naturales redunde en beneficio de los municipios en que se integren $\mathrm{y}$, en definitiva, de Andalucía. Es necesario, pues, implicar en la conservación de la naturaleza a los sectores económicos, pues en otro caso la política impulsada desde la Administración quedaría vacía de contenido, al faltar el apoyo de la población afectada, de forma que toda actuación que pretenda desconocer la interrelación entre la naturaleza y el desarrollo resulta a la larga frustrada.

A este respecto, Montserrat (1977) apunta que la palabra desarrollo indica el intento de hacer progresar lo que ya tiene existencia, ya vive, y puede ser reactivado, potenciado, no suplido por otra cosa sin relación con ella.

Uno de los aprovechamientos tradicionales en estos ENP es la ganadería, del tipo calificado actualmente como extensivo, practicada durante siglos, y que actualmente se ve afectada por la pérdida de rentabilidad del sector; lo que está desencadenando un proceso de intensificación que alienta las críticas hacia un supuesto impacto negati- vo sobre los recursos naturales (RodríguezEstévez et al., 2010a).

Cabe esperar que en los ENP se cuiden con especial énfasis los valores ambientales, sirviendo como puntos de referencia o escenarios demostrativos desde los que ensayar y exportar al resto del territorio modelos ambientalmente sostenibles (como la agricultura y la ganadería extensivas tradicionales) que incluyan en el balance de resultados, los beneficios de la conservación (Gómez-Limón et al., 2000).

\section{LA GANADERÍA EXTENSIVAEN ESPAÑA}

Durante los últimos cuarenta años, la ganadería española ha adquirido un gran desarrollo, dando lugar a una potente y eficiente ganadería intensiva (aves, cerdos, vacuno de leche y cebaderos de carne), independiente del medio y con gran consumo de inputs energéticos y materias primas importadas, en detrimento de la ganadería extensiva, con el consiguiente abandono de los recursos naturales propios (Mata Moreno, 2011). De esta forma, España ocupa actualmente el segundo lugar de Europa en número de ovinos (después del Reino Unido), de caprinos (después de Grecia) y de porcinos (detrás de Alemania) y el cuarto en número de bovinos (después de Francia, Alemania y Reino Unido) (INE, 2010). España es además, el tercer productor de carne, el cuarto de huevos y el sexto de leche de la UE.

Sin embargo, a pesar de los drásticos cambios acaecidos en las últimas décadas, la ganadería extensiva aún conserva una gran trascendencia porque con bajas producciones (aunque de gran calidad) y poco consumo de energía fósil, puede mantenerse con eficacia de forma sostenible y duradera (Rodríguez Pascual, 2007). Para ello, se apoyan en la utilización de las especies y razas autóctonas capaces de aprovechar eficazmente los recursos naturales mediante el pastoreo, permitiendo una explotación 


\section{GANADERÍA ECOLÓGICA EN LOS ESPACIOS NATURALES PROTEGIDOS ANDALUCES}

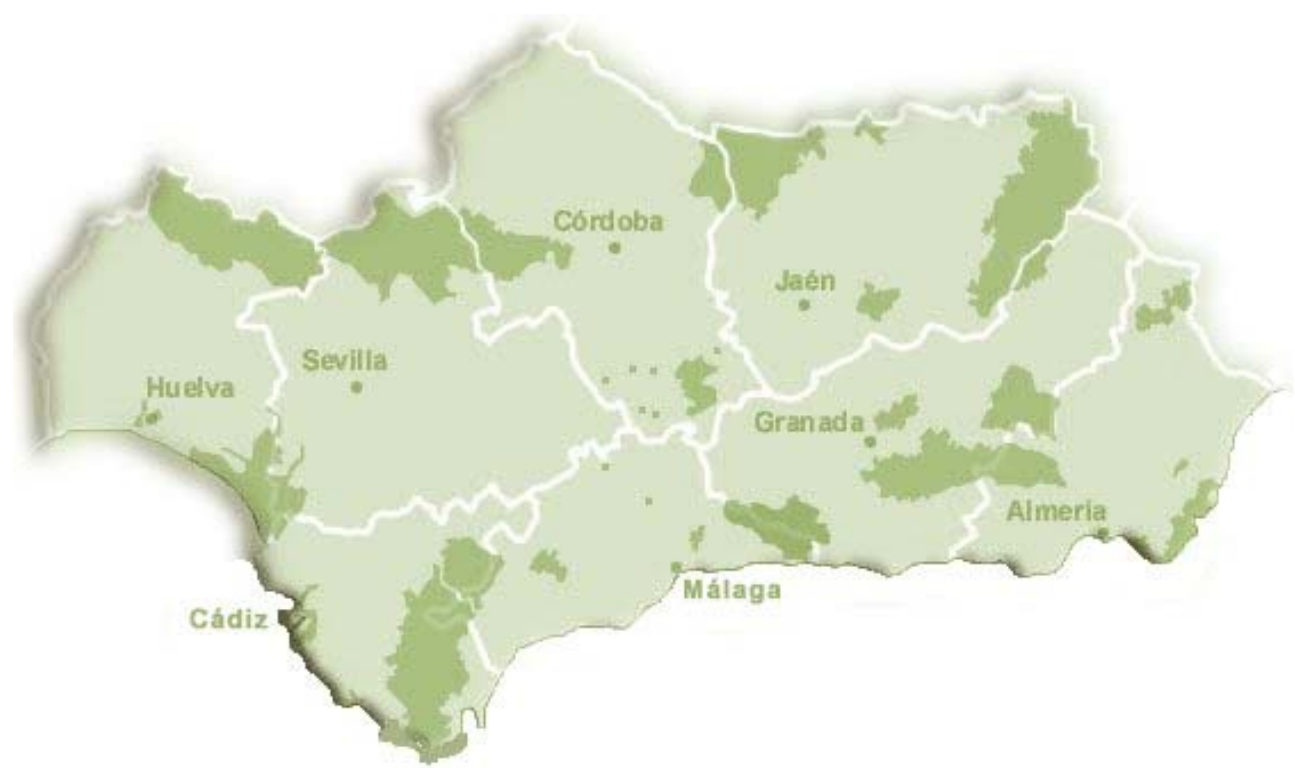

Fuente: Consejería de Medio Ambiente. Junta de Andalucía (2012).

Figura 1. Red de espacios naturales protegidos de Andalucía.

racional moderada que permite la regeneración del medio, sin llegar a su agotamiento (Hidalgo, 1996; García Romero y Cordero Morales, 2006).

En la actualidad en España no existe una definición oficial de ganadería extensiva. En líneas generales, se entiende por ganadería extensiva aquella en la que los animales obtienen la mayor parte de sus recursos alimenticios del entorno mediante pastoreo, integrándose en el medio y manteniendo un equilibrio con éste que permite la renovación estacional de esos recursos (Rodríguez-Estévez et al., 2007b).

Tan sólo en el caso del porcino la derogada Orden de 30 de junio de 1982, de ordenación sanitaria y zootécnica de las explotaciones porcinas extensivas (MAPA, 1982), define como Sistema de producción porcina extensiva el que se realiza en explotaciones que cuentan con recursos naturales adecuados para su aprovechamiento por el cerdo en régimen de pastoreo organizado racionalmente durante las fases de cría, recría y cebo. Según dicha orden las explotaciones de cría producen lechones para la venta y deben producir en la propia explotación recursos alimenticios suficientes para cubrir en condiciones normales al menos el $60 \%$ de las necesidades de alimentación del efectivo porcino; las Explotaciones de recría mantienen cerdos desde el destete hasta el cebo y deben producir al menos el $50 \%$ de los recursos alimenticios necesarios; y las explotaciones de cebo en montanera engordan a los cerdos mediante el aprovechamiento de temporada de bellota y pastos, debiendo producir al menos el $50 \%$ de los recursos alimenticios que necesitan esos animales. Sin embargo, esta condición se ha perdido con el nuevo RD 1221/ 2009 de Ordenación de explotaciones porcinas extensivas (MARM, 2009), en el que, en esencia, la extensividad se asocia al pastoreo como forma de obtención de los recursos nutritivos del medio, pero el límite se establece en base a una carga ganadera (CG) máxima de 2,4 UGM/ha (unidad gana- 
dera mayor), equivalente a 15 cerdos de cebo/ha, lo que imposibilita que los animales puedan obtener de la explotación los recursos alimenticios que necesitan en los porcentajes que fijaba la Orden de 30 de junio de 1982; teniendo en cuenta que, según indican Rodríguez-Estévez et al. (2010c), en la práctica, el momento en que más CG admite una dehesa es en montanera y generalmente sólo hay recursos para el pastoreo de 1 cerdo/ha, siempre y cuando no haya suplementación alimenticia.

Según Marten y Jordan (1972), la CG se define como el número de animales por unidad de superficie de pasto, que puede ser fija, cuando se mantiene el número de animales por unidad de superficie durante toda la estación de pastoreo, y variable, cuando se practica el sistema de ajuste de carga. La CG es la cantidad de UGM por unidad de superficie que existe en un determinado área (Paladines, 1992) durante un tiempo establecido (Ohlenbusch, 1994), siendo una UGM el equivalente a un animal de la especie bovina con más de dos años de edad (Consejería de Agricultura y Pesca, 2006).

En cuanto a CG, las restricciones que realmente existen, como indican (RodríguezEstévez et al. (2007b), son las relativas al manejo y distribución de deyecciones; como la Ley 29/1985, de 2 de agosto, de Aguas (Jefatura del Estado, 1985) y el Real Decreto 849/86, de 11 de abril (MOPU, 1986), donde se prohíbe acumular residuos sólidos o sustancias que constituyan o puedan constituir un peligro de contaminación para las aguas o su entorno. Más recientemente la Directiva 91/676/CEE, de Protección de aguas contra la contaminación producida por los nitratos procedentes de fuentes agrarias (CEE, 1991a), y el Real Decreto 261/ 1996, de 16 de febrero (Ministerio de la Presidencia, 1996), indican que del primer al cuarto año de actividad se podrán excretar hasta $210 \mathrm{~kg}$ de $\mathrm{N}$ por ha y a partir del quinto hasta un máximo de $170 \mathrm{~kg}$ de $\mathrm{N}$ por ha.

Aunque la bibliografía aporta diferentes cifras de producción y composición de ex- crementos (Rodríguez-Estévez, 2001), a efectos de planificación, el número máximo de animales productores de excretas por hectárea de terreno lo proporcionaba el primer Reglamento para la GE, el Reglamento CE 1804/99 (CEE, 1999), que establecía el aporte máximo en $170 \mathrm{~kg}$ de N/ha/año e indicaba el correspondiente número máximo de animales por hectárea y año a efectos del reparto de excretas. Posteriormente, esta carga fue refrendada por el Reglamento CE 889/2008 (CEE, 2008).

Combinando estas cifras con la producción de deyecciones por cabeza se pueden deducir los máximos de cargas ganaderas (tabla IV) para que toda la ganadería que se califique como extensiva cumpla con la Directiva 91/676/CEE de Protección de aguas contra la contaminación por nitratos procedentes de fuentes agrarias (CEE, 1991a) y el Real Decreto 261/1996 (Ministerio de la Presidencia, 1996). Sin embargo, de acuerdo con Rodríguez-Estévez et al. (2010b), el nuevo real decreto (MARM, 2009) incurre en un error cuando establece las cargas ganaderas en función de la eliminación de nitrógeno fecal en lugar de hacerlo a partir de la disponibilidad y consumo de recursos pascícolas.

Actualmente la ganadería extensiva no puede competir en términos económicos con la ganadería intensiva, pero sí en términos de rentabilidad social (fija y frena la despoblación) y medioambiental. Por eso existe la necesidad de mantener en el futuro un cierto equilibrio entre la ganadería intensiva, generadora de productos de amplio consumo y bajo precio (porcino, aves, huevos), pero con generación de residuos que es necesario gestionar adecuadamente, y la ganadería extensiva, que ofrece alimentos a los que se les supone una mayor calidad y un precio más alto, que además tienen el valor añadido de conservar el medio natural y consolidar población (Rodríguez Pascual, 2007); aunque por ello no reciban ningún pago compensatorio.

Para una adecuada gestión de la gana- 
Tabla IV. Producción de nitrógeno y excretas por la ganadería de acuerdo con el Reglamento (CE) 889/2008 para la Ganadería Ecológica (CEE, 2008). (Production of nitrogen and excreta from livestock according to EC Regulation 889/2008 for Organic Farming (EEC, 2008).

\begin{tabular}{lccccc}
\hline & $\begin{array}{c}\mathrm{kgN} / \\
\text { cabeza/ } \\
\text { año }\end{array}$ & $\begin{array}{c}\text { ha } \\
\text { necesarias/ } \\
\text { cabeza/año }\end{array}$ & $\begin{array}{c}\text { № máximo } \\
\text { animales/ } \\
\text { ha/año }\end{array}$ & $\begin{array}{c}\mathrm{kg} \\
\text { excretas/ } \\
\text { cabeza/día }\end{array}$ & $\begin{array}{c}\mathrm{kg} \\
\text { excretas/ } \\
\text { cabeza/año }\end{array}$ \\
\hline $\begin{array}{l}\text { Équidos <6 meses } \\
\text { Terneros de engorde y otros }\end{array}$ & 85.0 & 0.50 & 2.0 & 25.0 & 9125 \\
$\begin{array}{l}\text { Bovinos de engorde <1 año } \\
\text { Bovinos de 1 a 2 años }\end{array}$ & 34.0 & 0.20 & 5.0 & 5.8 & 2117 \\
Bovinos machos $>$ 2 años & 51.5 & 0.30 & 3.3 & 30.0 & 10950 \\
Terneras para cría y engorde & 85.0 & 1.00 & 2.0 & & \\
Vacas lecheras (producción y reposición) & 68.0 & 0.40 & 2.5 & & \\
Otras vacas & 85.0 & 1.00 & 2.0 & 55.0 & 20075 \\
Ovejas & 68.0 & 0.40 & 2.5 & 55.0 & 20075 \\
Ovino de engorde & 12.8 & 0.08 & 13.3 & 2.5 & 913 \\
Cabras & 12.8 & 0.08 & 13.3 & 2.5 & 365 \\
Caprino de engorde & & & & 1.0 & 365 \\
Lechones & 2.3 & 0.01 & 74.0 & 3.0 & 1095 \\
Cerdas reproductoras & 26.2 & 0.15 & 6.5 & 10.0 & 3650 \\
Cerdos de engorde con pienso y otros & 12.1 & 0.07 & 14.0 & 6.0 & 2190 \\
\hline
\end{tabular}

Fuente: CEE (2008) y Rodríguez-Estévez (2001).

dería en los ENP y para garantizar su sostenibilidad resulta imprescindible conocer la capacidad de carga ganadera (CCG) y la carga ganadera (CG), que es el único factor ecológico controlable por el ganadero (Mata et al., 2000).

Allen et al. (2011) definen la CG como la relación entre el número de animales y la superficie total de la tierra utilizada durante un tiempo determinado; una relación animal-tierra en el tiempo. Mientras que la CCG, es la cantidad de UGM por unidad de superficie (CG) que es capaz de soportar un territorio conservando su estado y condición (Gastó et al., 1993). Galt et al. (2000) la definen como el número medio de animales en una superficie determinada que se sustenta en el tiempo. Se denomina Presión de Pastoreo a la relación existente entre la CG y la CCG (Gómez Castro et al., 1974).

La posibilidad de que un animal pueda desarrollarse en un hábitat determinado depende de en qué medida este pueda atender a sus necesidades vitales, que son distintas según la especie animal; siendo las relativas a alimentación, agua y cobertura las más importantes para la mayoría (Caballero, 1985). Por esta razón, los modelos de CCG no deben basarse solamente en la disponibilidad de recursos alimenticios, ya que su distribución en el hábitat y su capacidad para cubrir los requisitos se rigen por la ley del mínimo de Liebig (Liebig, 1840) y por la teoría del optimal foraging (MacArthur y Pianka, 1966). La ley del mínimo de Liebig dice que el nutriente disponible en menor cantidad es el que limita la producción, aun cuando los demás estén en cantidades suficientes; y la teoría del optimal foraging señala que los organismos escogen su alimento de modo que obtienen el máximo beneficio energético con el mínimo costo posible, de manera que el proceso de captura y manipulación del alimento debe ser 
menos costoso que los beneficios energéticos obtenidos.

Todos estos parámetros tienen una variabilidad estacional que condiciona la evolución de la CCG, de tal manera que, normalmente, durante la estación más limitada en recursos alimenticios, la CCG será determinante en el caso de que los animales no puedan desplazarse a otras zonas más ricas en recursos (trashumancia o migración), a menos que se modifiquen los factores que la limitan durante esa época con la aportación de alimentos suplementarios (Mata Moreno et al., 2004). En hábitats de tipo mediterráneo con especies del género Quercus, la alimentación invernal suele estar asegurada, siendo el verano, cuando la hierba se seca y pierde calidad, la estación que presenta más limitaciones (Olea y San Miguel Ayanz, 2006).

En este sentido, Wallmo et al. (1977) señalan que la CCG estacional sería equivalente al número de animales necesario para consumir la mitad de la biomasa forrajera disponible y producida estacionalmente. Plata et al. (2011) compara otros modelos que estiman la CCG en función de la disponibilidad de nutrientes (McCall et al., 1997), de la presión de pastoreo (Paladines y Lazcano, 1983) y del metabolismo ecológico (Moen, 1978; Clemente, 1984). El primer modelo se basa en la disponibilidad de MS, ED y $\mathrm{N}$ en cada uno de los estratos vegetales presentes en el área estudiada; el segundo, se basa en la disponibilidad de MS (total o de cada estrato) y en la presión de pastoreo asignada (en función del peso vivo y la época del año) y el tercero se basa en una estimación del requerimiento energético (EM, kcal/día) de acuerdo a la época del año y a los cambios de actividad del ganado. La Ley 1/1986, de 2 de mayo, sobre la Dehesa en Extremadura (Asamblea de Extremadura, 1986) utiliza una metodología para el cálculo de la CCG que tiene en cuenta el número de raciones anuales de mantenimiento de ovejas tipo (atribuible por equivalencia al total del ganado existente en la dehesa), el tiempo que dentro del año el ganado o parte de él permanece alimentándose fuera de la dehesa, los suplementos alimenticios proporcionados al ganado o parte de él durante el año (distintos de los recursos naturales propios de la dehesa) y el tiempo que dentro del año han estado aprovechando estos recursos otros animales ajenos a la dehesa (dentro o fuera de la misma).

La CCG en los ENP no puede establecerse únicamente con los criterios pastorales clásicos de la ganadería extensiva (cantidad y calidad de los pastos disponibles), sino en función, también, de las necesidades de regeneración de los estratos leñosos y de las necesidades de conservación de la biodiversidad vegetal y animal (Montoya, 1999). Además, teniendo en cuenta su especial fragilidad, el pastoreo debería manejarse con especial cuidado, definiéndose una carga de compatibilidad biológica (máxima carga admisible que resulta compatible con la conservación de determinadas especies animales o vegetales) que tenga en cuenta la relación entre la CG silvestre y la vegetación; siendo ésta una de las cuestiones más importantes en la conservación de muchos ENP (Montoya, 1999).

\section{LAGANADERÍA EXTENSIVAEN ANDALUCÍA}

En Andalucía, la ancestral cultura ganadera, los condicionantes del medio físico y las circunstancias socioeconómicas, han permitido que la ganadería extensiva siga teniendo especial relevancia dentro de las producciones ganaderas totales; así, de acuerdo con Rodríguez Estévez et al. (2003) bajo distintas formas y con diferentes grados de pastoreo, en ganadería extensiva se producían en Andalucía en 2003 el $71 \%$ del vacuno mayor de dos años, el $97 \%$ del ovino reproductor, el $50 \%$ del caprino reproductor y el $27 \%$ del porcino reproductor.

Una gran parte de esta ganadería extensiva se distribuye sobre los PN ligada a zonas rurales desfavorecidas con suelos 
pobres de escasa rentabilidad agraria, y encuentra un medio ideal en las dehesas y en las sierras ubicadas en los PN (RodríguezEstévez et al., 2003).

\section{LA GANADERÍA EXTENSIVA EN LOS PARQUESNATURALES ANDALUCES}

Aunque la ganadería que se practica en los PN es básicamente extensiva, la situación y nivel de explotación ganadera, resultan ser asuntos muy complejos y sensibles tanto para los ganaderos (por lo referente a las restricciones que se le imponen con el argumento de la protección medioambiental), como para los responsables de los PN y la sociedad en general (por el posible impacto medioambiental negativo de una sobreexplotación ganadera). Esta situación ha desembocado en frecuentes choques de intereses entre los ganaderos y la administración de los PN, siendo escasos los espacios de diálogo donde se aborde esta problemática (Rodríguez-Estévez et al., 2010a).

Por ello son necesarios estudios relati- vos a los usos ganaderos y cinegéticos en estas zonas protegidas. Pero lo habitual hasta ahora ha sido la estimación de censos ganaderos o cinegéticos independientes, sin integrar en una única CG la suma de ambas poblaciones (Garin, 2000) ya que es difícil desarrollar censos de fauna silvestre; son diferentes los colectivos profesionales que estudian la ganadería y la explotación cinegética, las competencias sobre ganadería y fauna y caza corresponden a administraciones diferentes; y los intereses de ganaderos y productores cinegéticos en líneas generales o no coinciden o están enfrentados.

En 1989, la Universidad de Murcia realizó un primer estudio para determinar los niveles de CG (y su efecto sobre los recursos naturales) en el PN de Sierra de Cazorla, Segura y Las Villas (Gallego Simón et al., 2003), lo que llevó a la administración de este PN a establecer planes para regular de forma efectiva la CG (Agencia de Medio Ambiente, 1993). Otros trabajos pioneros en este sentido son los de Passera y

Tabla $\boldsymbol{V}$. Porcentajes de superficies infrautilizadas, sobrecargadas y en equilibrio en los parques naturales de Andalucía. (Percentages of underutilized, overgrazed and balanced areas in Natural Parks of Andalusia).

\begin{tabular}{lccc}
\hline Parques naturales & Infrautilizada & En equilibrio & Sobrecargada \\
\hline Entorno Natural de Doñana & 14,31 & 70,32 & 15,37 \\
Montes de Málaga & 0 & 92,33 & 7,67 \\
Sierra de Andújar & 6,02 & 82,37 & 11,61 \\
Sierra de Aracena y Picos de Aroche & 17,22 & 64,07 & 18,7 \\
Sierra de Baza & 41,19 & 50,03 & 8,78 \\
Sierra de Cardeña y Montoro & 8,17 & 77,23 & 14,6 \\
Sierra de Castril & 0 & 72,16 & 27,84 \\
Sierra de Cazorla, Segura y las Villas & 19,79 & 75,24 & 4,96 \\
Sierra de Grazalema & 33,04 & 46,34 & 20,61 \\
Sierra de Hornachuelos & 20,82 & 74,13 & 5,05 \\
Sierra de Huétor & 34,69 & 26,42 & 38,9 \\
Sierra de las Nieves & 0,34 & 80,45 & 19,29 \\
Sierra de los Alcornocales & 17,23 & 64,63 & 7,87 \\
Sierra de Mágina & 14,86 & 72,92 & 12,21 \\
\hline
\end{tabular}

Fuente: Rodríguez Estévez et al. (2003). 
Tabla VI. Importancia de la ganadería de rumiantes en los PN andaluces medida en UGM (Census (UGM = LU) of ruminant livestock farming in Andalusian Natural Parks (UGM = LU).

\begin{tabular}{lccccc}
\hline & Andalucía & Extensivo & En los PN & \% total en los PN & \% extensivo en los PN \\
\hline Vacuno & 311421 & 215262 & 95728 & 30,7 & 44,5 \\
Ovino & 352024 & 341006 & 49747 & 14,1 & 14,6 \\
Caprino & 177325 & 88663 & 21885 & 12,3 & 24,7 \\
Total rumiantes & 840770 & 644931 & 167360 & 19,9 & 26,0 \\
\hline
\end{tabular}

1 vaca $=1$ UGM; 1 oveja o cabra= 0,15 UGM (Decreto 14/2006 (Consejería de Agricultura y Pesca, 2006a). Fuente: Rodríguez-Estévez y Mata Moreno (2002).

Allegretti (1993), Cano Carmona y RuizMartínez (1996) y Bermejo (2003) y Rodríguez-Estévez et al. (2003) (tabla V). La novedad de los trabajos de RodríguezEstévez et al. (2003) es incluir las CG cinegética y doméstica, cuya suma conduce a un $66 \%$ de superficie equilibrada, 18 $\%$ de superficie sobre explotada y $16 \%$ de supeficie infrautilizada desde el punto de vista pascícola en el conjunto de los PN andaluces.

La ganadería extensiva es un aprovechamiento tradicional en los PN. De hecho, Rodríguez-Estévez y Mata Moreno (2002) subrayan la evidente asociación de la ganadería extensiva y los PN, ya que el $26 \%$ de las UGM de los rumiantes andaluces se explotan en régimen extensivo y el $20 \%$ se asienta en el 14,3\% del territorio que suponen los PN (tabla VI).

\section{LA PROPIEDAD DE LA TIERRA EN LOS PARQUESNATURALES}

La expansión reciente de las figuras de protección ha afectado mayoritariamente a terrenos de propiedad particular, alterando radicalmente el criterio imperante hasta la década de los setenta, según el cual los ENP debían configurarse sobre tierras de propiedad pública dominante (Mulero, 2002). La complicada situación que plantean las grandes redes autonómicas de espacios protegidos, asentadas sobre regímenes de propiedad privada (principalmente en los PN de
Andalucía Occidental) y de propiedad pública (principalmente en los de Andalucía Oriental), ha sido estudiada por Font y Majoral (2000), Cascos y Guerra (2000) y Mulero (2000) y la distribución de ambas titularidades puede apreciarse en la tabla VII para 14 PN.

De acuerdo con Rodríguez-Estévez et al. (2003), las fincas ganaderas de los PN, por lo general, se asientan sobre propiedad privada, mientras que las áreas serranas con pastos de montaña por encima de los 1400 metros se asientan sobre propiedad pública (municipal, más los montes públicos de las administraciones autonómicas y nacional).

Aunque cada vez es más frecuente la aceptación de los ENP entre las poblaciones locales, aún es necesario seguir trabajando en la implicación de la sociedad en el mantenimiento orientado a los objetivos de gestión del territorio (Rodríguez Estévez et al., 2007b). Los desacuerdos con las comunidades locales suelen derivar del conflicto con intereses particulares o públicos, del desajuste con la realidad socioeconómica del territorio afectado, o de una inadecuada comprensión de las funciones de las actividades agropecuarias que permiten el funcionamiento de los sistemas naturales (Gómez-Limón et al., 2000).

Estos desacuerdos son constatados por López-i-Gelats et al. (2009) en áreas rurales de montaña, observando que el cambio rural está dando lugar a un proceso de diversificación de las opiniones sobre el futuro del 


\section{GANADERÍA ECOLÓGICA EN LOS ESPACIOS NATURALES PROTEGIDOS ANDALUCES}

medio rural y las estrategias de desarrollo a seguir. En este sentido señalan cuatro grandes maneras de entender el medio rural y la ganadería de montaña: el discurso pro-ganadero, que justifica los clásicos valores de la agricultura; el discurso conservacionista, con una gran influencia de valores urbanos; el discurso emprendedor, con una visión claramente economicista, pero con referentes locales o regionales; y el discurso del desarrollo endógeno, que defiende una estrategia de desarrollo basada en una diversificación económica dirigida por la población local.

En el caso de la propiedad privada mayoritaria, los conflictos lo son con los propietarios individualmente considerados y no con la colectividad que habita en el territorio del PN (Valle Buenestado, 1995). Una excesiva presencia patrimonial pública dificulta la inserción de los mecanismos de mercado en la atribución de valor a los recursos naturales e impide el desarrollo de dinámicas de rentas a los ciudadanos del ámbito rural (Martínez Salcedo, 1993).

Pero es incuestionable que tanto las nuevas legislaciones como los PORN, han impuesto limitaciones a la forma de ejercitar la propiedad y han modificado diversos hábitos tradicionales en la gestión de los predios rústicos implicados; como también es indudable que la razón jurídica en este asunto asiste a las administraciones públicas competentes (Rodríguez-Estévez et al., 2003).

El problema reside en que las limitaciones y restricciones aludidas, al no afectar en la misma medida a las fincas colindantes no incluidas en el perímetro de protección, suponen una clara discriminación para las primeras; que no reciben ningún tipo de compensación por ese motivo. Esto ha impulsado la oposición y confrontación de propietarios, asociaciones de ganaderos y agricultores, y ha generado conflictos de distinta índole a lo largo de toda la geografía española. El hecho de que algunos ENP se hayan creado englobando casi exclusi-

Tabla VII. Porcentajes de propiedad pública y privada en parques naturales andaluces. (Percentages of public and private property in 14 Andalusian Natural Parks).

\begin{tabular}{lll}
\hline Parques naturales & Privada & $\begin{array}{c}\text { Tipo de propiedad } \\
\text { Pública }\end{array}$ \\
\hline Montes de Málaga & $3 \%$ & $97 \%$ \\
Sierra de Andújar & $75 \%$ & $25 \%$ \\
Sierra de Aracena y Picos de Aroche & $89 \%$ & $11 \%$ (de la cual el $90 \%$ es municipal) \\
Sierra de Baza & $14 \%$ & $86 \%$ (de la cual el $20 \%$ es municipal) \\
Sierra de Cardeña- Montoro & $88,8 \%$ & $11,2 \%$ \\
Sierra de Castril & $3 \%$ & $97 \%$ municipal con derechos de \\
& & servidumbre \\
Sierra de Cazorla, Segura y las Villas & $13 \%$ & $87 \%$ (de la cual al menos el $15 \%$ es \\
& & municipal) \\
Sierra de Hornachuelos & $94 \%$ & $5 \%$ (de la cual el $1 \%$ es municipal) \\
Sierra de las Nieves & $36 \%$ & $64 \%$ (de la cual el $78 \%$ es municipal) \\
Sierra de los Alcornocales & $68 \%$ & $32 \%$ municipal \\
Sierra de Mágina & $85 \%$ & $15 \%$ \\
Sierra Norte & $95 \%$ & $5 \%$ \\
Sierras Subbéticas & $96 \%$ & $4 \%$ (de la cual el $80 \%$ es municipal) \\
\hline
\end{tabular}

Fuente: Rodríguez-Estévez et al. (2003). 
vamente propiedades privadas, y sin contraprestaciones, ha repercutido negativamente en la actitud de los propietarios de fincas. Esta situación es preocupante porque sin su colaboración los objetivos de la protección pueden verse truncados (Mulero, 2002).

Aunque los ganaderos son conscientes de la importancia que tiene su labor en el manejo y conservación de los ecosistemas pastoriles, no han sido capaces de transmitir su papel protagonista como conservadores del medio. Por eso les resulta difícil aceptar que se les acuse a todos de no conservar, y de que su ganado pueda ser valorado como un riesgo (RodríguezEstévez et al., 2010b). Sin embargo, en la mayoría de los casos los ganaderos son los conservadores históricos de las áreas naturales, por cultura, paisaje, conocimientos y usos tradicionales.

Además en los ENP, donde las talas y los desbroces cuentan con estrictas limitaciones, la estructura y la composición de la vegetación de las fincas depende primordialmente del pastoreo; y éste es imprescindible para la formación y mantenimiento de los agroecosistemas, como la dehesa (Rodríguez-Estévez et al, 2007b); declarada en 2002 como Reserva de la Biosfera por la UNESCO (en concreto, las dehesas de Sierra Morena) por su reconocido valor ecológico, ambiental y cultural (Marañón et al., 2012). De este modo el ganado, manteniendo en mínimos el estrato arbustivo, se convierte en la primera herramienta para evitar los incendios forestales que suponen el más fuerte azote para los ecosistemas mediterráneos (Rodríguez-Estévez et al., 2007b). Pero además, el ganado introduce heterogeneidad al paisaje. Sus querencias y caminos, sus diversos efectos sobre las distintas comunidades vegetales, su alteración física del suelo, e incluso sus deyecciones crean diversidad estructural, y ello se traduce en diversidad biológica (San Miguel, 2001). Así, la conservación de los agroecosistemas pasa por mantener los procesos de influencia antrópica que los originaron y mantuvieron en una evolución conjunta (Muñoz-Igualada y Guil, 2005), en la que uno de los actores y resultados es la diversidad genética y la adaptación de las razas autóctonas (García Romero y Cordero Morales, 2006; Rodríguez-Estévez et al., 2007a).

Afortunadamente, las falsas imágenes y percepciones de todos los gestores de los ENP, como ultraconservadores del medio, o de todos los ganaderos como sobreexplotadores del medio, ya van cambiando y se va admitiendo que hay sensibilidades diferentes sobre el medio natural, su conservación y explotación (Rodríguez-Estévez etal., 2010a).

En una encuesta de opinión realizada con motivo de la reunión anual EUROPARCEspaña, celebrada en 1998 entre los gestores y administradores de los ENP sobre las implicaciones socioeconómicas derivadas de su existencia, se identificaron entre los principales efectos sociales positivos la mejora de la educación ambiental y la sensibilización de la población, y desde el punto de vista económico la creación de nuevas expectativas de negocio y la posibilidad de oferta de productos locales (Múgica et al., 2010b).

\section{LA GANADERÍA Y LA SUSTENTABILIDAD}

La planificación, diseño y gestión del uso de la tierra exige un cuidadoso equilibrio que permita alcanzar la máxima eficacia y sostenibilidad; lo cual resulta muy complejo debido a las interacciones existentes entre el medio ambiente, la economía y la sociedad (Beinat y Nijkamp, 2007).

Al final de los años sesenta, se instaura el concepto de desarrollo sostenible, perdurable o sustentable como resultado de la sensibilidad creciente ante los problemas medioambientales surgidos al violar los límites de la naturaleza mediante la explotación y crecimiento económico descon- 
trolados (Meadows et al., 1972). En este concepto se pretendía integrar y asociar las dimensiones económica y social con la dimensión ecológica (Cardoso y Faletto, 1975). Pero la sustentabilidad, o sostenibilidad, es un concepto complejo y en evolución, que evidencia la necesidad de un proceso que permita integrar medioambiente con desarrollo, y a la vez, economía con ecología (Toro et al., 2010).

Según se señala en el Informe Brundtland (Comisión Mundial sobre Medio Ambiente y Desarrollo, 1987), el desarrollo sostenible se define como aquel que atiende a las necesidades del presente sin comprometer las posibilidades de las generaciones futuras para satisfacer sus propias necesidades. El desarrollo sostenible se ha convertido en uno de los tópicos mundiales más populares de la agenda política de casi todos los gobiernos, que se comprometen en este empeño mediante la integración del bienestar económico, la calidad ambiental y la coherencia social (Böhringer y Jochem, 2007).

Entre las diversas acepciones de sustentabilidad, una de las más utilizadas es la de la Comisión Mundial sobre Medio Ambiente y Desarrollo (1987), que la define como la relación entre los sistemas humano y ecológico que permite mejorar y desarrollar la calidad de vida, manteniendo, al mismo tiempo, la estructura, las funciones y la diversidad de los sistemas que sustentan la vida. En otras palabras podría conceptuarse como la viabilidad de la relación que mantiene un sistema socioeconómico con un ecosistema (Naredo, 1994).

La sustentabilidad ecológica encuentra su punto de referencia en la sociedad sostenible que, desde la perspectiva ecológica, se define como aquella que conserva los sistemas ecológicos sustentadores de la vida y de la biodiversidad, garantiza la sustentabilidad de los recursos renovables, reduce a un mínimo el agotamiento de los recursos no renovables, y se mantiene dentro de la CCG de los ecosistemas susten- tadores (Allende, 2000).

Thompson y Nardone (1999) plantean que la evaluación de la sostenibilidad de los sistemas extensivos de producción animal se puede aplicar a las complejas relaciones existentes entre la CG, el pasto, el matorral y la vida salvaje. Estos elementos de los sistemas pastorales pueden permanecer en equilibrio durante prolongados periodos de tiempo, pero el desequilibrio puede aparecer de repente, como consecuencia de un cambio crítico en alguno de los elementos.

En la actualidad, el desarrollo de la ganadería está en relación con las preocupaciones de la sociedad, donde la sostenibilidad aparece como una de las cuestiones clave (Gibon et al., 1999; Selfa et al., 2008). Por tanto, el concepto de sostenibilidad es un enfoque básico para el futuro desarrollo de la investigación en los sistemas de explotación ganadera. Actualmente van paralelos el estudio de la competitividad y la sostenibilidad productiva, es decir, el análisis de sistemas de producción económicamente eficientes con un aprovechamiento óptimo de los recursos; particularmente en aquellos con balances ecológicos complejos (Boyazoglu, 2002), como pueden ser los sistemas ganaderos extensivos (Gibon et al., 1999).

En estos sistemas ganaderos extensivos el cambio más significativo desde los años 80 ha sido producido por la política agraria comunitaria (PAC) que, a pesar de haber fomentado la extensificación, fijó unos niveles de referencia muy superiores a los tradicionales, con lo que se estimuló la intensificación de estos sistemas (Martín Bellido et al., 2001; Rodríguez-Estévez et al., 2007b). La política comunitaria de las subvenciones ha inducido a estas explotaciones a aumentar su producción con el fin de obtener una mayor renta y situarse, en términos de competitividad, en condiciones aceptables respecto a otros sistemas de producción, a costa de sobreexplotar espacios naturales muy importantes (Gaspar, 2007). Pero, teniendo en cuenta los efectos 
negativos del sobrepastoreo en el ecosistema (falta de regeneración de la vegetación y degradación y erosión del suelo) y que la intensificación de estos sistemas ganaderos extensivos está muy ligada a los intentos de mejorar su rentabilidad, parece necesario encontrar el equilibrio que permita su persistencia (Gaspar, 2007).

\section{LA EVALUACIÓN DE LA SUSTENTABILIDAD}

Desde la mitad de la década de los 90, numerosas metodologías han sido desarrolladas para evaluar la efectividad del manejo de las áreas protegidas (Ej. Bernúes et al., 2005; Hockings, 2003; Naughton-Treves et al., 2005).

Según diversos autores (Kates et al., 2001; Devuyst et al., 2001; y Ness et al., 2007) el objetivo de la evaluación de la sustentabilidad es proporcionar a los encargados de adoptar decisiones una valoración de ámbito local a global que integre los sistemas de naturaleza y sociedad a corto y largo plazo, a fin de ayudar a determinar qué acciones deben o no deben ser emprendidas para favorecer una sostenible relación entre sistemas.

La sustentabilidad no es una situación de momento o una condición estática, sino que corresponde a un proceso verificable sólo con el transcurrir del tiempo, lo que implica que su evaluación es el resultado de análisis periódicos (López y Mantilla, 2006). Por tanto, la definición del grado de sustentabilidad es, a menudo, la predicción de que las medidas adoptadas hoy conduzcan a la sustentabilidad en el futuro (Toro $e t$ al., 2010).

Hockings (2003) indica que para evaluar la efectividad del manejo de las áreas protegidas (ENP) se pueden utilizar dos tipos de datos: datos cuantitativos procedentes del seguimiento de las explotaciones y datos cualitativos derivados de la evaluación de gestores y productores.

En diversos agroecosistemas se han utilizado distintas metodologías para evaluar la sustentabilidad, desde unas muy detalladas, sólo aplicables a condiciones experimentales, a otras muy generales, pasando desde la simple toma de datos en campo, por encuestas y entrevistas, y llegando hasta la predicción mediante ecuaciones de regresión y modelos de simulación (Toro et al., 2010).

En la evaluación de la sustentabilidad en general y en el caso particular de su aplicación en los agroecosistemas, la herramienta básica de evaluación son los indicadores y los índices (Sarandón, 2002). Consisten en medidas sencillas, la mayoría cuantitativas, que representan un estado de los derechos económicos, sociales y/o del desarrollo del medio ambiente en una región definida, a menudo en el plano nacional (Hodge et al., 1999; López y Mantilla, 2006; Toro et al., 2010). Cuando los indicadores son agregados de alguna manera, la medida resultante es un índice (Atkinson et al., 1997; Mayer, 2008; Ness et al., 2007).

La principal desventaja del uso de indicadores e índices de sostenibilidad recae en la dificultad para diagnosticar las causas de insostenibilidad, así como para evaluar los efectos de las intervenciones propuestas (Smith y McDonald, 1998); no obstante, la principal ventaja consiste en hacer operativo el concepto de sostenibilidad agraria permitiendo medirlo, aunque de forma aproximada (Sánchez, 2009).

Existen evidencias históricas de la sostenibilidad de la ganadería extensiva (tradicional) en serranías y dehesas. Pero las formas de vida y las organizaciones sociales de la ganadería tradicional en gran parte son antiguas y están superadas; y la historia debe continuar, pero las soluciones duraderas a estos problemas ecológicos y económicos sólo pueden encontrarse sobre la base de la recuperación de las producciones tradicionales y mediante la mejora de la productividad de los recursos pascícolas (Campos Palacín, 1983). Los sistemas de explotación ganadera en régimen 
extensivo, normalmente localizados en áreas de montaña y tradicionalmente caracterizados como de baja intensidad o baja utilización de insumos externos, son cruciales a la hora de mantener la biodiversidad y el paisaje cultural o tradicional sobre el que se asientan (Bernués, 2007). El modelo de sostenibilidad de la ganadería tradicional debe servir de inspiración para nuevos modelos de gestión que, como en el caso de la GE, sean compatibles con las actuales circunstancias sociales (Mata Moreno et al., 2004).

\section{LA GANADERÍA TRADICIONAL: SUS VALORES Y LAS CAUSAS DE SU CRISIS}

Los conocimientos sobre la ganadería extensiva están dispersos, sin formar un cuerpo doctrinal o teoría general que se adapte a todos los ecosistemas pastorales de nuestro país; cada uno requiere su propio manejo (Rodríguez-Estévez, 2005). Una de las pocas recopilaciones sobre el conocimiento ganadero tradicional es la realizada por Mata Moreno et al. (2004) en la sierra de Cádiz.

La ganadería tradicional se ha orientado siempre más a la continuidad que a la producción máxima, tratando de reducir las fluctuaciones, y emplear cantidades mínimas o nulas de energía externa (combustibles, pienso, fertilizantes, etc.). Este planteamiento corresponde a un modelo de sostenibilidad, basado en el uso casi exclusivo de los recursos locales mediante una gestión cuidadosa que ha permitido la pervivencia de sus diferentes sistemas (Rodríguez-Estévez, 2005). Sin embargo, en la segunda mitad del siglo XX, determinadas circunstancias ocasionan el declive de la ganadería extensiva: bajos beneficios de los sistemas extensivos tradicionales, falta de competitividad frente a la ganadería intensiva, cambios sociales, envejecimiento de la población (brecha generacional), dependencia climática, deficientes vías de comercialización y producción a pequeña escala (Boza López, 1996; Mata Moreno et al., 2004).

Los intentos de modernización optaron primeramente por la intensificación, la reducción de la mano de obra y la sustitución de la trashumancia y trasterminancia por la adquisición de suplementos y piensos (Mata Moreno, 2004). Las ayudas o las subvenciones, llevaron al agricultor y al ganadero a orientar sus producciones hacia modelos que no sólo no garantizaban la sostenibilidad del sistema, sino que al disociar el binomio ganadería-agricultura, rompieron el equilibrio del ecosistema agropecuario tanto en el entorno de la dehesa como en las sierras que constituyen el territorio de los PN (Rodríguez-Estévez et al., 2007a).

Según Campos Palacín (1983), esa intensificación se acompañó en numerosas ocasiones de la ampliación de la superficie de cultivos destinados al consumo humano (trigo, girasol, etc.), arrancándose para tal fin muchos encinares de los mejores majadales de la dehesa. Además, se fue modificando la composición de la ganadería dando lugar a un aumento de la carga ganadera, a una regresión del ganado autóctono $\mathrm{y}$ a un aumento porcentual del vacuno, disminuyéndose la eficacia en el aprovechamiento de los pastos y dificultándose la regeneración de la vegetación; teniéndose que aumentar considerablemente el uso de fertilizantes químicos y de piensos concentrados. En las zonas menos productivas de las explotaciones disminuyó la presión de pastoreo, con lo que el monte bajo invadió la superficie de pastos; mientras que en las más productivas, la presión aumentó, llevando a muchas tierras a una lenta pero implacable desforestación (por la imposibilidad de regeneración de la arboleda), y a la erosión.

Muchos de estos ecosistemas no han podido soportar el costo ambiental de esa intensificación, derivada de la adaptación a unas reglas económicas cada vez más desvinculadas de las peculiaridades 
Tabla VIII. Carga ganadera media de las explotaciones ganaderas ecológicas de los parques naturales de Andalucía (RodríguezEstévez et al., 2010a). (Average stocking rate in organic farms of Andalusian Natural Parks).

\begin{tabular}{lc}
\hline Parque natural & UGM/ha \\
\hline Despeñaperros & 0,79 \\
Doñana & 0,15 \\
Los Alcornocales & 0,21 \\
Montes de Málaga & 0,36 \\
S. de Aracena y Picos de Aroche & 0,18 \\
S. de Baza & 0,12 \\
S. de Cardeña y Montoro & 0,36 \\
S. de Castril & 0,27 \\
S. de Grazalema & 0,13 \\
S. de Hornachuelos & 0,23 \\
S. de las Nieves & 0,35 \\
S. Mágina & 0,23 \\
S. Nevada & 0,06 \\
S. Norte & 0,29 \\
S. de Andujar & 0,28 \\
S. de Cazorla, Segura y Las Villas & 0,36 \\
S. Subbéticas & 0,31 \\
\hline Media de los parques naturales & 0,22 \\
\hline
\end{tabular}

ecológicas de los sistemas de producción locales (Gastó Corderch et al., 2010). Así, por ejemplo, la Orden conjunta de 6 de abril de 1999 (Consejería de Agricultura y Pesca, 1999a y 1999b) permitió cobrar primas por extensificación hasta con 1,4 UGM/ha; sin embargo, de acuerdo con Rodríguez-Estévez et al. (2010a) la CG media de los ganaderos ecológicos de los PN andaluces es de 0,22 $\mathrm{UGM} / \mathrm{ha}$ (con CG medias por PN entre 0,06 y 0,79 UGM/ha) (tabla VIII).

Estas transformaciones y efectos, suponen además el riesgo añadido de perder el saber asociado a las prácticas sostenibles de la ganadería tradicional (Mata Moreno et $a l ., 2004)$. La sabiduría tradicional tiene mucho que ofrecer en términos de vivir en armonía con la naturaleza y en sociedad, siendo éste uno de los principios fundamentales del concepto sustentabilidad
(Mebratu, 1998). Diversos trabajos (Montserrat, 1977; Barrios et al., 1992; Rodríguez-Estévez et al., 2007b) indican que han sido los ganaderos y agricultores tradicionales los que con su saber ecológico han mantenido este importante legado en la dehesa y en los espacios serranos de montaña. Actualmente son sus herederos o los nuevos propietarios los que tienen la responsabilidad de la gestión de estas fincas ganaderas y de la conservación de su medio físico, pero para ello la actividad ganadera debe ser rentable (Rodríguez-Estévez et al., 2012).

De acuerdo con González Bernáldez, en el prólogo de El saber ecológico de los ganaderos de la Sierra de Madrid (Barrios et al., 1992), el conocimiento tradicional o saberes ecológicos de los ganaderos y agricultores europeos sólo pueden ser ya recogidos in extremis, en las regiones menos afectadas por el cambio tecnológico agrícola y acudiendo a las clases de edad más avanzadas. Dentro de muy poco será imposible averiguar casi nada acerca de una cultura de personas que ni escribieron ni publicaron, y a la que se accede sólo por experiencia directa. Y sin embargo, nos es necesario disponer de esos conocimientos y acceder a la comprensión de los variados sistemas de uso del suelo que durante siglos modelaron los ecosistemas y paisajes europeos.

En la misma línea se expresa Montserrat (1977): El hombre integrado en un ecosistema con topografía e historia, puede constituir algo muy adecuado para obtener de dicha circunstancia el provecho máximo sin merma de la estabilidad. El pastoreo y ramoneo reiterativos, bien ordenados, estructuraron el paisaje vegetal y sus rebanos, pero siempre bajo la inteligente mirada de unos pastores compenetrados, inmersos en tal sistema extraordinario y casi extinguido. Estos hombres beneméritos y ridiculizados por sus hermanos ciudadanos están desapareciendo; queda su espectro en unos viejos sin ilusión o en 
chicos que sólo esperan encerrar sus animales para jugar; antes jugaban a pastor, ahora esperan redimirse hasta ser como los ciudadanos que pueden vivir. Se les educa para la ciudad, enseñándoles a odiar el campo donde han nacido. Hemos perdido la baza del regulador-pastor, y sólo nos queda jugar la del seto-cancilla, para ordenar el pastoreo sin estar siempre pendientes del rebaño y sus hatos. No se trata de salvar un animal o una planta, sino unos sistemas que funcionan con hombres seleccionados a lo largo de los siglos.

Para romper esta dinámica, además de reconducir las políticas y orientaciones técnicas equivocadas, se necesitan ganaderos jóvenes bien adaptados al medio, empapados de la cultura tradicional, implicados en el desarrollo de las zonas rurales, que sepan leer el paisaje y tengan en cuenta todos sus condicionantes para manejar adecuadamente ecosistemas complejos como los que se incluyen en numerosos PN y ENP. No obstante, la cultura tradicional debe también evolucionar y adaptarse al siglo XXI e incorporar todos los conocimientos científicos y técnicos que se generan continuamente en las universidades y centros de investigación (Rodríguez Pascual, 2007) y buscar todas las posibilidades de diferenciación y valor añadido que oferte.

\section{LAGANADERÍA ECOLÓGICA COMO ACTIVIDAD SOSTENIBLEENLOS ESPACIOSNATURALES PROTEGIDOS}

Entre los modelos medioambientalmente sostenibles con diferenciación en el mercado y protección legal se encuentran la agricultura y la ganadería ecológica (GE), que son producciones que se han venido desarrollando en toda la UE desde 1992 y que surgen como respuesta a la demanda social de una actividad agraria respetuosa con el medio ambiente (Mata Moreno, 2004).

El principal objetivo de la GE es ofrecer a la población alimentos de origen animal de la máxima calidad sanitaria, nutritiva y organoléptica conservando el medio y el entorno natural, respetando el bienestar y la protección de los animales, y evitando el empleo sistemático de sustancias químicas de síntesis y de organismos genéticamente modificados (Kijlstra y Eijck, 2006; Mata Moreno, 2001).

La legislación europea que regula las producciones ganaderas ecológicas es doble: el Reglamento (CE) 834/2007 de 28 de junio de 2007 que trata sobre producción y etiquetado de los productos ecológicos y por el que se deroga el Reglamento (CEE) 2092/91 (CEE, 2007), y el Reglamento (CE) $889 / 2008$ de 5 de septiembre de 2008 por el que se establecen disposiciones de aplicación del Reglamento (CE) 834/2007 (CEE, 2008).

El marco legal de la GE conduce a diseñar sistemas de manejo propios que permitan, en cada circunstancia, conseguir un agroecosistema estable en el que los animales aprovechen los recursos forrajeros existentes, permitiendo todas las técnicas de la agricultura y ganadería convencional que sean compatibles con la normativa legal vigente (Mata Moreno, 2001). De acuerdo con Mata Moreno et al. (2004), la GE encuentra su mejor modelo en la ganadería extensiva tradicional.

Las producciones ecológicas en la UE se encuentran enmarcadas dentro de los programas agroambientales, que se adoptan principalmente para reducir la pérdida de la biodiversidad (Rundlöf et al., 2008). Esta biodiversidad resulta vital para el sustento de muchos de los habitantes de las zonas protegidas, jugando un importante papel en la estrategia de gestión de sus explotaciones, no sólo a la hora de producir alimentos, sino también a la hora de ofrecer otros servicios complementarios (Davies et al., 2012).

Rodríguez-Estévez et al. (2003 y 2010a) opinan que, en los PN, no se debería de practicar otra ganadería distinta a la que 
garantice su sostenibilidad y contribuya a la conservación del entorno natural. En este sentido, la ganadería extensiva alcanza su máximo reconocimiento oficial bajo el amparo de la certificación como GE; por lo que esta modalidad ganadera se convierte en una opción viable y acorde para compatibilizar la conservación medioambiental con el desarrollo rural (Ronchi y Nardone, 2003).

Según Grandi y Triantafyllidis (2010), las producciones ecológicas son especialmente adecuadas en las explotaciones situadas en los PN ya que no están sometidas a contaminación externa y son muy ricas en biodiversidad, lo que resulta crucial para la protección del medio. Además, señalan que estas producciones promueven ayudas compensatorias para los agricultores y ganaderos por su labor como guardianes/ administradores de la naturaleza, lo que contribuye a estabilizar las poblaciones rurales en esas zonas.

Rodríguez-Estévez et al. (2010a) indican que la GE presenta múltiples razones para ser el sistema de explotación de los ENP con más futuro; ya que es una opción voluntaria de producción regulada, sometida a control e inspección, y certificada, por lo que puede facilitar a la administración el cumplimiento que de esas tareas en los ENP. Además, en un mercado ávido de productos diferenciados, es un valor añadido con ventajas para la comercialización que indudablemente contribuye al desarrollo rural. Por otra parte, la GE es garantía de conservación y aprovechamiento racional de los recursos naturales, debiéndose guardar una estrecha proporción entre la CG y la superficie disponible, que permita mantener bajo control los problemas derivados del sobrepastoreo y de la erosión, a fin de evitar todo impacto negativo en el medio ambiente; particularmente en el suelo, las aguas superficiales y las capas freáticas; además, los altos precios de la alimentación suplementaria procedente de la agricultura ecológica hacen que sea inviable una deriva hacia la intensificación (Díaz Gaona, 2013).
Finalmente, conviene resaltar que la existencia de un control e inspección realizado por organismos independientes reduce los conflictos entre la administración y los ganaderos; así, la comprobación de los niveles ecológicos de las CG (o la evaluación de los efectos del pastoreo) es realizada por inspectores de los organismos de control y certificación autorizados en GE (que comprueban el cumplimiento de la normativa con todos sus matices) de manera imparcial e independiente, tal y como exige la norma EN45011 (AENOR, 1998), sirviendo de árbitro e intermediario, evitando tensiones y conflictos de intereses entre ambos.

La GE convierte a la ganadería y a la agricultura en una pieza clave del ecosistema y devuelve al ganadero su protagonismo como conservador y artífice del paisaje. Pues, tal y como demuestra la historia, ha sido la ganadería sostenible tradicional, como base de las economías autárquicas del pasado, el único medio de subsistencia en este amplio territorio, que no admitiendo otros tipos de explotación, ha llegado hasta nuestros días en un estado de conservación y equilibrio tales que ha merecido su protección al amparo de la figura de los PN (Rodríguez-Estévez, 2005; RodríguezEstévez et al., 2012).

Andalucía se encuentra a la cabeza de España en protección del territorio y en producción ganadera ecológica. Por este motivo, las políticas y modelos de gestión aplicados en Andalucía sobre los PN y sobre la GE son de gran influencia en el conjunto nacional (Rodríguez-Estévez et al., 2010a). Como indican Grandi y Triantafyllidis (2010), a pesar de las diferencias que pueden existir entre las zonas protegidas de diferentes áreas, muchos de los problemas a los que se enfrentan hoy día son muy similares.

Según señalan Rodríguez-Estévez et al . (2010a), la GE se practica en 18 de los 20 PN no costeros de Andalucía, con un total de 187265 ha y 728 ganaderos registrados, lo que supone más de un $30 \%$ de las explota- 


\section{GANADERÍA ECOLÓGICA EN LOS ESPACIOS NATURALES PROTEGIDOS ANDALUCES}

ciones ganaderas ecológicas registradas en Andalucía, en un territorio protegido que sólo englobaba el 19,5\% de la región.

Estas cifras parecen demostrar que los ganaderos de los PN andaluces tienen una buena disposición hacia la GE y sus valores como sistema de explotación agraria, aunando producción y conservación; lo que puede elevar de categoría la labor del ganadero, transformándolo en conservador de la naturaleza, además de productor primario.

Por estas razones y en este contexto de conflicto de intereses, la GE se plantea como la opción más viable y sostenible para compatibilizar los intereses económicos de los ganaderos, el desarrollo rural y la conservación medioambiental en los ENP (Mata Moreno, 2004).

\section{CONCLUSIONES}

En España, la ganadería extensiva supone uno de los aprovechamientos más importantes de los realizados en los ENP, siendo tradicionalmente una actividad sostenible ligada a la explotación de razas autóctonas y al aprovechamiento de los pastos.

La asociación entre la ganadería extensiva y los ENP es evidente, por la necesidad de vinculación equilibrada a un territorio productor de pastos; pero la intensificación de esta ganadería y las restricciones, manejo del territorio y gestión de los recursos naturales, impuestas a los productores de

\section{BIBLIOGRAFÍA}

AENOR. 1998. Requisitos generales para entidades que realizan la certificación de producto. (Guía ISO/CEI 65:1996).

Agencia de Medio Ambiente. Junta de Andalucía. 1993. Resolución de 17 de agosto de 1993, por la que se aprueba el plan de aprovechamiento ganadero del parque natural de las Sierras de Cazorla, Segura y las Villas. BOJA, 102.

Allen, V.G.; Batello, C.; Berretta, E.J.; Hodgson, J.; Kothmann, M.; Li, X.; Mclvor, J.; Milne, J.; Morris, C.; Peeters, A. and Sanderson, M. 2011. An esas zonas, están poniendo en riesgo la sostenibilidad del sistema, tanto la medioambiental como la económica.

Teniendo en cuenta que el ganado en pastoreo mantiene diversidad biológica y contribuye al control de los incendios forestales, su presencia es interés para la conservación y el equilibrio de estos territorios. Pero es imprescindible que en los ENP se practique una modalidad ganadera que permita alcanzar el equilibrio entre conservación medioambiental y rentabilidad económica, como promueve la GE (además de desarrollo rural, que también debe de ser uno de los objetivos de las políticas de ENP). Esta GE encuentra su mejor base en la ganadería extensiva tradicional. Una de las ventajas de la GE es el caráter voluntario de los controles a los que se somenten las explotaciones ganaderas, facilitando los requerimientos de la administración de los ENP (evitar contaminación, erosión, sobrepastoreo, etc.); además de promover ayudas compensatorias para los agricultores y ganaderos por su labor como conservadores de la naturaleza.

Sería conveniente que en aquellos ENP con más superficie y posibilidades y tradiciones ganaderas se diseñen y caractericen los modelos de producción ecológica más sostenibles, para que puedan ser seguidos por otros productores y extrapolados a otras áreas.

international terminology for grazing lands and grazing animals. Grass Forage Sci, 66: 2-28.

Allende, J. 2000. Medio ambiente, ordenación del territorio y sostenibilidad. Servicio Editorial. Universidad del País Vasco. Bilbao. España.

Asamblea de Extremadura. 1986. Ley 1/1986, de 2 de mayo, sobre la Dehesa en Extremadura. BOE, 184: 26393-6402.

Atkinson, G.; Dubourg, R.; Hamilton, K.; Munasignhe, M.; Pearce, D. and Young, C. 1997. Measuring sustainable development: macro- 


\section{DÍAZ GAONA, SÁNCHEZ RODRÍGUEZ, GÓMEZCASTRO Y RODRÍGUEZESTÉVEZ}

economics and the environment. Edward Elgar Publishing. Cheltenham, UK.

Barrios, J.C.; Fuentes, M.T. y Ruiz, J.P. 1992. El saber ecológico de los ganaderos de la Sierra de Madrid. Agencia de Medio Ambiente de la Comunidad de Madrid. Madrid. España.

Beinat, E. and Nijkamp, P. 2007. Multicriteria analysis for land-use management: environment \& management. Kluwer Academic Publishers. Dordrecht. The Netherlands.

Bermejo, L.A. 2003. Conservación de los recursos genéticos caprinos en los espacios protegidos de Canarias: impacto social y ambiental. Tesis doctoral. Universidad de Córdoba. España. pp. 47-93.

Bernués A. 2007. Ganadería de montaña en un contexto global: evolución, condicionantes y oportunidades. Pastos, 37: 133-175.

Bernúes, A.; Riedel, J.L.; Asensio, M.A.; Blanco, M.; Sanz, A.; Revilla, R. and Casasús, I. 2005. An Integrated approach to studying the role of grazing livestock systems in the conservation of rangelands in a protected natural park (Sierra de Guara, Spain). Lives Prod Sci, 96: 75-85.

Böhringer, C. and Jochem, P. 2007. Measuring the immeasurable. A survey of sustainability indices. Ecol Econ, 63: 1-8.

Boyazoglu, J. 2002. Livestock research and environmental sustainability with special reference to the Mediterranean basin. Small Ruminant Res, 45: 193-200.

Boza López, J. 1996. Papel de los pequeños rumiantes en los ecosistemas áridos mediterráneos. http://www.racve.es/actividades/detalle/id/87 (01/01/2011).

Caballero García, R. 1985. Hábitat y alimentación del ciervo en ambiente mediterráneo. ICONA. Ministerio de Agricultura Pesca y Alimentación. Madrid. España.

Campos Palacín, P. 1983. La degradación de los recursos naturales de la dehesa. Análisis de un modelo de dehesa tradicional. Agricultura $y$ Sociedad, 265: 289-380.

Cano Carmona, E. y Ruiz Martínez, I. 1996. Modelos de capacidad de carga para el ciervo y para la ganadería ovino-caprino (razas autóctonas) en Parques Naturales de Jaén. Diputación Provincial de Jaén. Instituto de Estudios Jiennenses. Jaén. España.

Cardoso, F. e Faletto, E. 1975. Dependência e desenvolvimento na América Latina. Zahar Editores. Río de Janeiro. Brasil.

Cascos, G. y Guerra, J.C. 2000. Los espacios naturales protegidos en Castilla y León: un plan ambicioso entre la escasez de medios y un futuro incierto. Geografía y Espacios Naturales Protegidos. Bol Asoc Geógrafos Esp, (Fuera de Serie): 75-102.

CEE. 1991a. Directiva 91/676/CEE del Consejo, de 12 de diciembre de 1991, relativa a la protección de las aguas contra la contaminación producida por nitratos utilizados en la agricultura. DO L 375 de 31/12/1991.

CEE. 1992. Directiva 92/43/CEE del Consejo, de 21 de mayo de 1992, relativa a la conservación de los hábitats naturales y de la fauna y flora silvestres. DOCE L 206/7 de 22/07/1992.

CEE. 1999. Reglamento (CE) 1804/99 del Consejo, de 19 de julio de 1999 por el que se completa, para incluir las producciones animales, el Reglamento (CEE) 2092/91 sobre la producción agrícola ecológica y su indicación en los productos agrarios y alimenticios. DOCE L 222 de 24/08/1999.

CEE. 2007. Reglamento (CE) 834/2007 del Consejo de 28 de junio de 2007 sobre producción y etiquetado de los productos ecológicos y por el que se deroga el Reglamento (CEE) 2092/91. DO L 189 de 20/07/2007.

CEE. 2008. Reglamento (CE) 889/2008 de la Comisión de 5 de septiembre de 2008 por el que se establecen disposiciones de aplicación del Reglamento (CE) 834/2007 del Consejo sobre producción y etiquetado de los productos ecológicos, con respecto a la producción ecológica, su etiquetado y su control. DO L 250 de 18/09/2008.

CEE. 2010. Directiva 2009/147/CE del Parlamento Europeo y del Consejo de 30 de noviembre de 2009 relativa a la conservación de las aves silvestres. DOCE L 20/7 de 26/01/2010.

Chape, S.; Harrison, J.; Spalding, M. and Lysenko, I. 2005. Measuring the extent and effectiveness of protected areas as an indicator for meeting global biodiversity targets. Philos Trans Roy Soc B, 360: 443-455.

Clemente, S.F. 1984. Utilización de la vegetación nativa del venado cola blanca (Odocoileus virginianus). Tesis de Maestría. Colegio de Postgraduados. Montecillo, Estado de México.

Archivos de zootecnia vol. 63 (R), p. 48. 


\section{GANADERÍA ECOLÓGICA EN LOS ESPACIOS NATURALES PROTEGIDOS ANDALUCES}

México.

Comisión Mundial sobre Medio Ambiente y Desarrollo. 1987. Nuestro futuro común (Informe Brundtland). Alianza Editorial, SA. Naciones Unidas. Madrid. España.

Consejería de Agricultura y Pesca. Junta de Andalucía. 1999a. Orden conjunta de 6 de abril de 1999, de las Consejerías de Agricultura y Pesca y de Medio Ambiente, por la que se establece un régimen de ayudas para fomentar en las dehesas andaluzas el empleo de métodos de producción agraria compatibles con las exigencias de la protección del medio ambiente y la conservación del espacio natural. BOJA, 50: 51075120.

Consejería de Agricultura y Pesca. Junta de Andalucía. 1999b. Orden conjunta de 6 de abril de 1999, de las Consejerías de Agricultura y Pesca y de Medio Ambiente, por la que se establece un régimen de ayudas para fomentar en determinados humedales y sus áreas de influencia y en las Zonas de Especial Protección para las Aves (ZEPAs), así como en sus áreas de influencia, el empleo de métodos de producción agraria compatibles con las exigencias de la protección del medio ambiente y la conservación del espacio natural. BOJA, 50: 5121-5141.

Consejería de Agricultura y Pesca. Junta de Andalucía. 2006a. Decreto 14/2006, de 18 de enero, por el que se crea y regula el Registro de Explotaciones Ganaderas de Andalucía. BOJA, 14: 9-14.

Consejería de Medio Ambiente. Junta de Andalucía. 2010. Red de espacios naturales protegidos de Andalucía. http://www.juntadeandalucia.es/ medioambiente/site/web/menuitem.486fc6e $1933804 \mathrm{f} 2 \mathrm{c} 562 \mathrm{ce} 105510 \mathrm{e} 1 \mathrm{ca} /$ ? vgnextoid= c349185968f04010VgnVCM1000001625 e 50 aRCRD\&vgnextchannel $=3259$ b $19 \mathrm{c}$ 7acf2010VgnVCM1000001625e50a RCRD\& Ir=lang_es (01/04/2011).

Consejería de Medio Ambiente. Junta de Andalucía. 2012. Red de espacios naturales protegidos de Andalucía. http://www.juntadeandalucia.es/ medioambiente/site/portalweb/menuitem. 7 e $1 \mathrm{cf} 46 \mathrm{ddf} 59 \mathrm{bb} 227 \mathrm{a} 9 \mathrm{ebe} 205510 \mathrm{e} 1 \mathrm{ca} /$ ?vgnextoid $=545 \mathrm{e} 0 \mathrm{bf} 41 \mathrm{a} 188110 \mathrm{VgnVCM}$ 1000000624 e50aRCRD\&vgnextchannel= 007fee9b421f4310VgnVCM2000000624e50a $\operatorname{RCRD}(01 / 08 / 2012)$.
Consejo de Europa. 2000. Convenio Europeo del Paisaje. Florencia. http://www.magrama.gob. es/en/desarrollo-rural/temas/desarrollo-territorial/090471228005d489_tcm11-24940.pdf (21/ 05/2014).

Davies, J.; Poulsen, L.; Schulte-Herbrüggen, B.; Mackinnon, K.; Crawhall, N.D.; Henwood, W.; Dudley, N.; Smith, J. and Gudka, M. 2012. Conserving dryland biodiversity. IUCN (International Union for the Conservation of Nature). Kenya.

Devuyst, D.; Hens, L. and Lannoy, W. 2001. How green is the city? Sustainability assessment and the management of urban environments. Columbia University Press. New York.

Díaz Gaona, C. 2013. La ganadería ecológica como modelo de gestión del Parque Natural Sierra de Grazalema. Tesis Doctoral. Universidad de Córdoba. España.

Domenech García, V.; Pardo Sempere, L.; García Martínez, A.; Frías Mora, J.J.; Herrera García, M. y Rodríguez Alcalde, J.J. 1999. El sector caprino extensivo en el contexto del Parque Natural de Cazorla, Segura y Las Villas. XXIV Jornadas SEOC. pp. 131-134.

Ferraro, P.J. 2008. Protected areas and human well-being. In: Economics and conservation in the tropics: A strategic dialogue. http://www. rff.org/Documents/08_Tropics_Conference/ Tropics_Conference_Papers/Tropics $\% 20$ Conference_Ferraro_Protected_Areas_and Human_Well-Being.pdf (16/04/2014).

Font, J. y Majoral, R. 2000. Los espacios naturales de protección especial en Cataluña. Monográfico sobre geografía y espacios protegidos. Asociación de Geógrafos Españoles-Federación de Espacios Naturales Protegidos de Andalucía. Murcia. España. pp. 113-142.

Gallego Simón, V.J.; Sánchez Martínez, J.D. y Araque Jiménez, E. 2003. Las conexiones entre la política forestal y de colonización agraria en el Alto Guadalquivir. En: Vázquez Valera, C. y García Marchante, J. (Eds.). Las relaciones entre las comunidades agrícolas y el monte. Asociación de Geógrafos Españoles. Cuenca. España. pp. 77-92.

Galt, D.; Molinar, F.; Navarro, J.; Joseph, J. and Holechek, J. 2000. Grazing capacity and stocking rate. Rangelands, 22: 7-11.

García Romero, C. y Cordero Morales, R. 2006. Ganadería ecológica y razas autóctonas. Edi- 


\section{DÍAZ GAONA, SÁNCHEZ RODRÍGUEZ, GÓMEZCASTRO Y RODRÍGUEZESTÉVEZ}

torial Agrícola Española. SEAE, ADGE. 112 pp. Garin, I. 2000. El Ciervo (Cervus elaphus) en la reserva de caza de la Garcipollera (Huesca). Ed. Consejo de Protección de la Naturaleza de Aragón. España. 140 pp.

Gaspar, P. 2007. Evaluación técnico-económica y caracterización de sistemas ganaderos extensivos en dehesas de Extremadura. Tesis Doctoral. Universidad de Extremadura. España.

Gastó Corderch, J.; Calzado Martínez, C.; Carbonero Muñoz, M.D.; De Pedro Sanz, E.; Fernández Rebollo, P.; Garrido Varo, A.; Gómez Cabrera, A.; Guerrero Ginel, J.E., Guzmán Álvarez, R.; Lara Vélez, P. y Ortiz Medina, L. 2010. Sostenibilidad de las dehesas. Documento de reflexión. Grupo de Desarrollo Rural de Los Pedroches. Córdoba. España.

Gastó, J., Cosio, F. y Panario, D. 1993. Clasificación de ecorregiones y determinación de sitio y condición. Red de Pastizales Andinos (Reepan). Santiago de Chile. 254 pp.

Gibon, A.; Sibbald, A.R.; Flamant, J.C.; Lhoste, P.; Revilla, R.; Rubino, R. and Sorensen, J.T. 1999. Livestock farming systems in Europe and its potential contribution for managing towards sustainability in livestock farming. Livest Prod Sci, 61: 121-137.

Gómez Castro, A.G., Medina Blanco, M., Peinado Lucena, E. 1974. Estado actual de los conocimientos sobre aprovechamiento de prados: Efecto de la carga ganadera sobre la producción animal. Zootechnia, 23: 547554.

Gómez-Limón, J.; Atauri, J.A.; Múgica, M.; De Lucio, J.V. y Puertas, J. 2008. Planificar para gestionar los espacios naturales protegidos. EUROPARC-España. Fundación Fernando González Bernáldez (FUNGOBE). Madrid. España.

Gómez-Limón, J.; De Lucio, J.V. y Múgica, M. 2000. Los espacios naturales protegidos del estado español en el umbral del siglo XX: de la declaración a la gestión activa. Fundación Fernando González Bernáldez (FUNGOBE). Madrid. España.

Grandi, C. and Triantafyllidis, A. 2010. Organic agriculture in protected areas. The italian experience. Natural Resources Management and Environment Department. Food and Agriculture Organization of the United Nations. Rome. Italia.
Heywood, V.H. and Iriondo, J.M. 2003. Plant conservation: old problems, new perspectives. Biol Conserv, 113: 321-335.

Hidalgo, S.J. 1996. Imbricaciones de los sistemas de producción extensiva en los ecosistemas naturales. En: La ganadería extensiva en los países mediterráneos de la Unión Europea: Situación actual y perspectivas. Junta de Extremadura. Consejo Regional de Colegios Oficiales de Veterinarios. Cáceres. España.

Hobbs, N.T.; Baker, D.L.; Ellis, J.E. and Swift, D.M. 1981. Botanical composition and nutritional quality of elk winter diets in the upper montane zone. J Wildl Manag, 45: 156-171.

Hockings, M. 2003. Systems for assessing the effectiveness of management in protected areas. BioScience, 53: 823-832.

Hodge, A.; Hardi, P. and Bell, D. 1999. Seeing change through the lens of sustainability. Paper for the Workshop: Beyond delusion: Science and policy dialogue on designing effective indicators of sustainable development. International Institute for Sustainable Development. Costa Rica.

INE. 2010. Producción ganadera. Datos europeos. Censo ganadero. http://www.ine.es/jaxi/tabla. do?path $=/$ t01/a097/e01/I0/\&file $=01001 . p x \&$ type $=$ pcaxis $\& L=0 \quad(01 / 08 / 2012)$.

IUCN (International Union for Conservation of Nature). 1994. Guidelines for protected area management categories. CNPPA and WCMC. IUCN. Gland. Switzerland and Cambridge. UK.

IUCN (International Union for Conservation of Nature). 2012. The IUCN Programme 2013-2016. IUCN World Conservation Congress. September 2012. https://cmsdata.iucn.org/downloads/ iucn_programme_2013_2016.pdf(11/03/2014). Jefatura del Estado. 1975. Ley 15/1975, de 2 de mayo, de espacios naturales protegidos. BOE, 107: 9419-9421.

Jefatura del Estado. 1985. Ley 29/1985, de 2 de agosto, de aguas. BOE, 189: 25123-25135.

Jefatura del Estado. 1989. Ley 4/1989, de 27 de marzo, de conservación de los espacios naturales y de la flora y fauna silvestres. $B O E, 74$ : 8262-8269.

Jefatura del Estado. 2007. Ley 42/2007, de 13 de diciembre, del patrimonio natural y de la biodiversidad. BOE, 299: 51275- 51327.

Kates, R.; Clark, W.; Corell, R.; Hall, M.; Jaeger, C.; 


\section{GANADERÍA ECOLÓGICA EN LOS ESPACIOS NATURALES PROTEGIDOS ANDALUCES}

Lowe, I.; McCarthy, J.; Schellnhuber, H.; Bolin, B.; Dickson, N.; Faucheux, S.; Gallopin, G.; Grubler, A.; Huntley, B., Jager, J.; Jodha, N.; Kasperson, R.; Mabogunje, A.; Matson, P. and Mooney, H. 2001. Sustainability science. Science, 292: 641-642.

Kijlstra, A. and Eijck, I.A.J.M. 2006. Animal health in organic livestock production systems: a review. NJAS-Wageningen. J Life Sci, 54: 7794.

Liebig, J.V. 1840. Chemistry and its applications to agricultura and physiology. Ed. L. Plaifair. Taylor and Walton. London.

López-i-Gelats, F., Tàbara, J.D., Bartolomé, J. 2009. The rural in dispute: Discourses of rurality in the Pyrenees. Geoforum, 40: 602-612.

López, J. y Mantilla, E. 2006. Los indicadores y la medición de la sostenibilidad. En: Mantilla, E. (Ed.). Medición de la sostenibilidad ambiental. Universidad Cooperativa de Colombia. Colombia.

MacArthur, R.H. and Pianka, E.R. 1966. On the use of a patchy environment. Amer Nat, 100: 603610.

MAPA. 1982. Orden de 30 de junio de 1982 por la que se establecen normas para el desarrollo de la ordenación sanitaria y zootécnica de las explotaciones porcinas extensivas. BOE, 180: 20529-20530.

Marañón, T.; Ibáñez, B.; Anaya-Romero, M. y Muñoz-Rojas, M. 2012. Estado y tendencia de los servicios de los ecosistemas forestales de Andalucía. Junta de Andalucía. Evenor. Sevilla. España.

MARM (Ministerio de Medio Ambiente y Medio Rural y Marino). 2009. Real Decreto 1221/2009, de 17 de julio, por el que se establecen normas básicas de ordenación de las explotaciones de ganado porcino extensivo y por el que se modifica el Real Decreto 1547/2004, de 25 de junio, por el que se establecen las normas de ordenación de las explotaciones cunícolas. BOE, 187: 66585-66597.

Marten, G.C. and Jordan, R.M. 1972. Put-and-take vs. fixed stocking for defining three grazing levels by lambs of alfalfa-orchardgrass. Agron J, 64: 69-72.

Martín Bellido, M.; Escribano Sánchez, M.; Mesías Díaz, F.J.; Rodríguez de Ledesma Vega, A. y Pulido García, F. 2001. Sistemas extensivos de producción animal. Arch Zootec, 50: 465-489.

Martínez Salcedo, F. 1993. La gestión de los espacios naturales en España. Revista Occidente, 149: 51-60.

Mata Moreno, C. 2001. Bases técnicas de la ganadería ecológica. In: CAAE (Ed.). La práctica de la agricultura y ganadería ecológicas. CAAE. Sevilla. España.

Mata Moreno, C. 2004. Ganadería ecológica. I Conferencia Internacional de Ganadería Ecológica en el Sur de Europa. Zamora. España. pp. 13-17.

Mata Moreno, C. 2011. La ganadería ecológica en el horizonte de 2020. Veterinarios, 1: 38-41.

Mata Moreno, C.; Rodero, A.; Rodero, M.L. y Lobillo, P. 2000. Uso racional ganadero en espacios naturales protegidos andaluces. Parque natural Sierra de Grazalema. Consejería de Medio Ambiente, Junta de Andalucía - Universidad de Córdoba. Sevilla. España.

Mata Moreno, C.; Maurer, P.; Rodríguez-Estévez, V. y Fernández, A. 2004. Recopilación del conocimiento ganadero tradicional de la comarca de la Sierra de Cádiz y su validación para la reconversión e implantación de la ganadería ecológica. Grupo Cordobés de Informática Multimedia. Córdoba. España.

Mautz, W.W. 1978. Nutrition and carrying capacity. In: Schmidt, J., Gilbert, D.L. (Eds). Big game of North America. Stackpole Books. Harrisburg, PA. USA. pp. 321-348.

Mayer, A. 2008. Strengths and weaknesses of common sustainability indices for multidimensional systems. Environ Inter, 34: 277-291.

McCall, T.C., Brown, R.D. and Bender, C.L. 1997. Comparison of techniques for determining the nutritional carrying capacity for white tailed deer. J Range Manage, 50: 33-38.

Meadows, D.H.; Meadows, D.L. and Randers, J. 1972. The limits to growth. Universe Books. New York.

Mebratu, D. 1998. Sustainability and sustainable development: Historical and conceptual review. Environ Impact Asses Rev, 18: 493-520.

Presidencia. Junta de Andalucía. 1989. Ley 2/ 1989, de 18 de julio, por la que se aprueba el inventario de espacios naturales protegidos de Andalucía y se establecen medidas adicionales para su protección. BOJA, 60: 27071-27129. Ministerio de la Presidencia. 1996. Real Decreto 


\section{DÍAZGAONA, SÁNCHEZRODRÍGUEZ, GÓMEZCASTROY RODRÍGUEZESTÉVEZ}

261/1996, de 16 de febrero, sobre protección de las aguas contra la contaminación producida por los nitratos procedentes de fuentes agrarias. BOE, 61: 9734-9737.

Moen, A.N. 1978. Seasonal changes in heart rates, activity, metabolism, and forage intake of white tailed deer. J Wild Manage, 42: 715-738.

Montoya, J.M. 1999. El ciervo y el monte: manejo y conservación. Mundi-Prensa. Madrid. España.

Montserrat, P. 1977. Algunos aspectos del desarrollo agropecuario andaluz. Pastos, 7: 5-28.

MOPU (Ministerio de Obras Públicas). 1986. Real Decreto 849/1986, de 11 de abril, por el que se aprueba el reglamento del dominio público hidráulico, que desarrolla los títulos preliminar I, IV, V, VI y VII de la Ley 29/1985, de 2 de agosto, de aguas. BOE, 103: 15500-15537.

Múgica, M., Atauri, J.A., Martínez, C., Puertas, J. y Gómez Limón, J. 2010a. Espacios naturales protegidos en España: balance hasta el año 2009. Quercus, 297: 38-45.

Múgica, M.; Martínez, C.; Gómez-Limón, J.; Puertas, J.; Atauri, J.A. y De Lucio, J.V. 2010b. Anuario EUROPARC-España del estado de los espacios naturales protegidos 2009. Fundación Fernando González Bernáldez (FUNGOBE). Madrid. España.

Múgica, M.; Martínez, C.; Gómez-Limón, J.; Puertas, J. y Atauri, J.A. 2012. Anuario 2011 del estado de las áreas protegidas en España. EUROPARC-España. Fundación Fernando González Bernáldez (FUNGOBE). Madrid. España.

Mulero, A. 2000. La red andaluza de espacios naturales protegidos: Proceso de configuración y cuestiones sin resolver. En: Valle Buenestado, B (Coord.). Geografía y espacios protegidos. AGE-FENPA. Murcia. España. pp. 253-272.

Mulero, A. 2002. La Protección de Espacios Naturales en España. Mundi Prensa. Madrid. España.

Muñoz-Igualada, J. y Guil, F. 2005. La dehesa y la sostenibilidad de un ecosistema frágil. Jornadas técnicas sobre la gestión ambiental y económica del ecosistema montado dehesa en la Península lbérica.

Naredo, J. 1994. Fundamentos de la economía ecológica. En: Aguilera, F., Alcántara, V. (Eds.). De la economía ambiental a la economía ecológica. Icaria. Barcelona. España.

Naughton-Treves, L.; Buck Holland, M. and
Brandon, K. 2005. The role of protected areas in conserving biodiversity and sustaining local livelihoods. Ann Rev Environ Res, 30: 219-252.

Ness, B.; Urbel-Piirsalu, E.; Anderberg, S. and Olsson, L. 2007. Survey: Categorizing tools for sustainability assessment. Ecol Econ, 60: 498508.

Ohlenbusch, P. 1994. Stocking rate and grazing management. Cooperative Extension Services. Kansas State University. U.S. pp. 1-6.

Olea, L. and San Miguel-Ayanz, A. 2006. The Spanish dehesa. A traditional Mediterranean silvopastoral system linking production and nature conservation. Sustainable grassland productivity. Proceedings of the $21^{\text {st }}$ General Meeting of the European Grassland Federation. Badajoz. Spain. pp. 3-13.

Paladines, O. y Lascano, C.E. 1983. Recomendaciones para evaluar germoplasma bajo pastoreo. En: Lascano, C.E. (Ed.). Germoplasma forrajero bajo pastoreo en pequeñas parcelas, Vol. 1. CIAT. Colombia. pp. 165-83.

Paladines, O. 1992. Metodología de pastizales para trabajar en fincas y proyectos de desarrollo agropecuario. Metodología. Manual 1: Pastos y forrajes. Proyecto de Fomento Ganadero Profogan. pp. 23-35.

Passera, C.B. y Allegretti, L.I. 1993. Evaluación pastoral y capacidad sustentadora de los pastos montanos del parque natural de la Sierra de Castril. Nutrición de rumiantes en zonas áridas y de montaña y su relación con la conservación del medio natural. Consejería de Agricultura y Pesca. Junta de Andalucía. España. pp. 87-94. Plata, F.X., Mendoza, G.D., Viccon, J.A., Bárcena, R. and Clemente, F. 2011. Comparison of methods based on the nutritional requirements and availability of biomass to estimate carrying capacity for white tailed deer. Arch Med Vet, 43: 41-50.

Pyke, G.H.; Pulliam, H.R. and Charnov, E.L. 1977. Optimal foraging: A selective review of theory and tests. Quart Rev Biol, 52: 137-154.

Rodríguez Pascual, M. 2007. La ganadería extensiva en España: importancia censal y medioambiental. http://www.ruralnaturaleza.com/ texto-la-ganaderia-extensiva-en-espana (01/ 02/2012).

Rodríguez-Estévez, V. 2001. Residuos ganaderos. En: ADGE, CAAE (Coord.). Principios téc- 


\section{GANADERÍA ECOLÓGICA EN LOS ESPACIOS NATURALES PROTEGIDOS ANDALUCES}

nicos de ganadería ecológica. CAAE. Sevilla. España. pp. 71-77.

Rodríguez-Estévez, V. 2005. Recopilar un conocimiento que se pierde. La Fertilidad de la Tierra, 22: 13-15.

Rodríguez-Estévez, V. y Mata Moreno, C. 2002. Ganadería sostenible en Andalucía. Papel de la dehesa en la nueva PAC. Libro blanco de la agricultura y el desarrollo rural. Jornada Autonómica de Extremadura. Sevilla. España. 12 de noviembre de 2002.

Rodríguez-Estévez, V.; Lobillo, J.R. y Rodero, M.L. 2003. La ganadería ecológica como alternativa de gestión en los parques naturales. Núñez de Prado-CAAE. Baena. España.

Rodríguez-Estévez, V.; Rucabado Palomar, T. y Mata Moreno, C. 2007a. Integración de las razas autóctonas en los espacios naturales protegidos de Andalucía. En: Rodero, E., Valera, M. (Coord.). La ganadería andaluza en el siglo XXI. Junta de Andalucía. Sevilla. España. pp. 279286.

Rodríguez-Estévez, V.; Rucabado Palomar, T. y Mata Moreno, C. 2007b. La producción ganadera extensiva y la conservación del medio ambiente en Andalucía. En: Rodero, E., Valera, M. (Coord.). La ganadería andaluza en el siglo XXI. Junta de Andalucía. Sevilla. España. pp. 267278.

Rodríguez-Estévez, V.; Díaz, C. y Sánchez, M. 2010a. La ganadería ecológica como herramienta de conservación de los parques naturales Andaluces. En: Analistas económicos de Andalucía (Coord.). Informe anual del sector agrario en Andalucía 2009. Analistas económicos de Andalucía Málaga. España. pp. 417-429.

Rodríguez-Estévez, V.; Díaz, C.; Sánchez, M. y Mata, C. 2010b. La dehesa como ejemplo de biodiversidad en la ganadería ecológica. Agricultura y Ganadería Ecológica, 0: 24-27.

Rodríguez-Estévez, V.; Sánchez-Rodríguez, M.; García, A. and Gómez-Castro, G. 2010c. Feed conversión rate and estimated energy balance of free grazing lberian pigs. Livest Sci, 132: 152-156.

Rodríguez-Estévez, V.; Sánchez-Rodríguez, M.; Arce, C.; García, A.R.; Perea, J.M. and GómezCastro, A.G. 2012. Consumption of acorns by finishing lberian pigs and their function in the conservation of the dehesa agroecosystem.
En: Kaonga, M.L. (Ed.). Agroforestry for Biodiversity and Ecosystem Services - Science and Practice. Intech. pp. 1-23. http://cdn. intechopen.com/pdfs-wm/34866.pdf (03/06/ 2013).

Ronchi, B. and Nardone, A. 2003. Contribution of organic farming to increase sustainability of Mediterranean small ruminants livestock systems. Livest Prod Sci, 80: 17-31.

Rundlöf, M.; Bengtsson, J. and Smith, H.G. 2008. Local and landscape effects of organic farming on butterfly species richness and abundance. $J$ Appl Ecol, 45: 813-820.

San Miguel, A. 2001. El pastoreo en la ordenación de los montes españoles del siglo XXI. En: III Congreso Forestal Nacional. Granada. España.

Sánchez, G. 2009. Análisis de la sostenibilidad agraria mediante indicadores sintéticos: aplicación empírica para sistemas agrarios de Castilla y León. Tesis doctoral. Departamento de Economía y Ciencias Sociales Agrarias. Escuela Técnica Superior de Ingenieros Agrónomos. Universidad Politécnica. Madrid. España.

Sarandón, S.J. 2002. La Agricultura como actividad transformadora del ambiente. El impacto de la agricultura intensiva de la Revolución Verde. En: Agroecología: El camino hacia una agricultura sustentable. Ediciones Científicas Americanas (ECA). La Plata. Argentina. pp. 23-47.

Selfa, T.; Jussaume, R.A. and Winter, M. 2008. Envisioning agricultural sustainability from field to plate: Comparing producer and consumer attitudesand practices toward environmentally friendly food and farming in Washington State, USA. J Rural Stud, 24: 262-276.

Smith, C.S. and McDonald, G.T. 1998. Assessing the sustainability of agriculture at the planning stage. J Environ Manage, 52: 15-37.

Thompson, P.B. and Nardone, A. 1999. Sustainable livestock production: methodological and ethical challenges. Livest Prod Sci, 61: 111-119.

Tolón Becerra, A. y Lastra Braco, X. 2008. Los espacios naturales protegidos. Concepto, evolución y situación actual en España. M+A. Rev Electrónic@de Medioambiente, 5: 1-25.https:/ /www.ucm.es/data/cont/media/www/pag41228/ART\%20A.TOLON\%20X.\%20LASTRA. pdf $(23 / 04 / 2014)$.

Toro, P.; García, A.; Gómez-Castro, A.G.; Perea, J.; Acero, R. y Rodríguez-Estévez, V. 2010. 


\section{DÍAZGAONA, SÁNCHEZ RODRÍGUEZ, GÓMEZ CASTROY RODRÍGUEZESTÉVEZ}

Evaluación de la sustentabilidad en agroecosistemas. Arch Zootec, 59: 71-94.

U.S. Fish and Wildlife Service. 1980. Habitat Evaluation Procedures (HEP). ESM 102. USDI Fish and Wildlife Service. Division of Ecological Services. Washington, D.C.

Vacas Guerrero, T. 2005. Los espacios naturales protegidos: figuras de protección en España. Actas del XIX Congreso de Geógrafos Españoles: Espacios públicos, espacios privados. Asociación de Geógrafos Españoles. Universi- dad de Cantabria. España.

Valle Buenestado, B. 1995. Propiedad y actividad agraria en espacios naturales protegidos, en Actas del VII Coloquio de Geografía Rural. Ponencias y Excursiones. Universidad de Córdoba. Diputación Provincial. Serie Estudios de Geografía no 9: 109-145.

Wallmo, O.C.; Carpenter, L.H.; Regelin, W.L.; Gill, R.B. and Baker D.L. 1977. Evaluation of deer habitat on a nutritional basis. J Range Manage, 30: 122-127. 